\title{
molecules
}

ISSN 1420-3049

www.mdpi.com/journal/molecules

Article

\section{Synthesis, Leishmanicidal and Cytotoxic Activity of Triclosan-Chalcone, Triclosan-Chromone and Triclosan-Coumarin Hybrids}

Elver Otero ${ }^{1}$, Sebastián Vergara ${ }^{1}$, Sara M. Robledo ${ }^{2,3}$, Wilson Cardona ${ }^{1, *}$, Miguel Carda ${ }^{4}$, Ivan D. Vélez ${ }^{2,3}$, Carlos Rojas ${ }^{5}$ and Felipe Otálvaro ${ }^{5}$

1 Química de Plantas Colombianas, Instituto de Química, Facultad de Ciencias Exactas y Naturales, Universidad de Antioquia UdeA, Calle 70 No. 52-21, A.A 1226 Medellín, Colombia;

E-Mails: elverluisotero@yahoo.es (E.O.); sebitasnano@hotmail.com (S.V.)

2 PECET, Instituto de Investigaciones Médicas, Facultad de Medicina, Universidad de Antioquia UdeA, Calle 62 No. 52-59, Lab 632, A.A 1226 Medellín, Colombia; E-Mails: sara.robledo@udea.edu.co (S.M.R.); ivan.velez@udea.edu.co (I.D.V.)

3 CIDEPRO-Center for Development of Products against Tropical Diseases, Carrera 53 No 61-30, Sede de Investigacion Universitaria, A.A 1226 Medellin, Colombia

4 Departamento de Química Inorgánica y Orgánica, Universidad Jaume I, E-12071 Castellón, Spain; E-Mail: mcarda@qio.uji.es

5 SIN-BIO-ME-NA, Facultad de Ciencias Exactas y Naturales, Universidad de Antioquia UdeA, Calle 70 No. 52-21, A.A 1226 Medellín, Colombia;

E-Mails: pipelion@quimica.udea.edu.co (F.O.); kimikrlos@hotmail.com (C.R.)

* Author to whom correspondence should be addressed; E-Mail: wilson.cardona1@udea.edu.co; Tel.: +574-219-5653; Fax: +574-233-0120.

Received: 19 May 2014; in revised form: 17 July 2014 / Accepted: 7 August 2014 / Published: 28 August 2014

\begin{abstract}
Twelve hybrids derived from triclosan were obtained via Williamson etherification of O-triclosan alkyl bromide plus chalcone and O-coumarin or O-chromone alkyl bromide plus triclosan, respectively. Structures of the products were elucidated by spectroscopic analysis. The synthesized compounds were evaluated for antileishmanial activity against $L$. (V) panamensis amastigotes. Cytotoxic activity was also evaluated against mammalian U-937 cells. Compounds 7-9 and 17, were active against Leishmania parasites $\left(\mathrm{EC}_{50}=9.4 ; 10.2 ; 13.5\right.$ and $27.5 \mu \mathrm{g} / \mathrm{mL}$, respectively) and showed no toxicity toward mammalian cells $(>200 \mu \mathrm{g} / \mathrm{mL})$. They are potential candidates for antileishmanial drug development. Compounds 25-27, were active and cytotoxic. Further studies using
\end{abstract}


other cell types are needed in order to discriminate whether the toxicity shown by these compounds is against tumor or non-tumor cells. The results indicate that compounds containing small alkyl chains show better selectivity indices. Moreover, Michael acceptor moieties may modify both the leishmanicidal activity and cytotoxicity. Further studies are required to evaluate if the in vitro activity against Leishmania panamensis demonstrated here is also observed in vivo.

Keywords: leishmaniasis; antiprotozoal; triclosan; coumarin; chromone; chalcone; hybrids

\section{Introduction}

Leishmaniasis is a group of diseases caused by protozoan parasites of the genus Leishmania, which infect and replicate inside macrophages of the vertebrate host. The diseases is a major health problem because is present in 98 countries and three territories worldwide, affecting mostly low-income people in rural areas of tropical and subtropical countries. Approximately 0.7 to 1.2 million cutaneous leishmaniasis (CL) cases occur annually. Afghanistan, Algeria, Colombia, Brazil, Iran, Syria, Ethiopia, North Sudan, Costa Rica and Peru, together account for $70 \%$ to $75 \%$ of global estimated CL incidence [1]. Leishmania (Viannia) panamensis is one of the most important causal agent of CL in Central and South America [2]. The different forms of leishmaniasis require expensive treatments, and the currently used medicines, pentavalent antimonials, pentamidine isothianate and miltefosine, show high toxicity and therefore severe side effects and therefore there is an urgent need for new drugs [3]. However, due to the lack of interest shown by the pharmaceutical industry to develop drugs against neglected diseases, it is necessary to join forces to develop new and better drugs to manage the disease and help patients to improve their quality of life [4].

Triclosan is an uncompetitive inhibitor of purified enoyl-acyl carrier protein reductase (ENR), which has demonstrated inhibitory activity in vitro against Plasmodium falciparum [5-8]. A previous study showed that triclosan and quinoline-triclosan hybrids with shorter spacers, that is three and five methylene units, have in vitro activity against axenic and intracellular amastigotes with effective concentration $\left(\mathrm{EC}_{50}\right)$ below of $24 \mu \mathrm{g} / \mathrm{mL}$ ) of Leishmania panamensis [9]. Similarly, antileishmanial activity of several chalcones has been reported [10-12]. The most promising of this class of compounds is licochalcone A, an oxygenated chalcone isolated from the roots of the Chinese plant Glycyrrhiza spp., which inhibits the fumarate reductase, a selective target present in the mitochondria of the parasite [13].

Coumarins and chromones are important classes of compounds having versatile biological activities [14-22]. Both moieties are well known for their antiprotozoal activity. Some synthetic chromones were effective against $L$. donovani [23] and L. major [24] in in vivo studies. Aurapten, a 7-geranyloxycoumarin, was extracted from the Rutaceae species Esenbeckia febrifuga. This compound shows significant growth inhibition with a $50 \%$ inhibitory concentration $\left(\mathrm{IC}_{50}\right)$ of $30 \mu \mathrm{M}$ against L. major [25]. Three coumarins isolated from the leaves of Galipea panamensis were tested against axenic amastigote forms of $L$. panamensis and displayed $50 \%$ effective concentrations $\left(\mathrm{EC}_{50}\right)$ of 9.9 , 10.5 , and $14.1 \mu \mathrm{g} / \mathrm{mL}$, respectively [26]. In addition, several 4-arylcoumarins were found to strongly inhibit 
the protozoan parasites of $L$. donovani, particularly 4-(3,4-dimethoxyphenyl)-6,7-dimethoxy-coumarin that exhibits potent activity on intracellular amastigotes with a selectivity index (SI) of 265, twice that shown by amphotericin B (SI = 140) [27].

The combination of two pharmacological agents into a single molecule, called hybrid molecule, is an emerging strategy in medicinal chemistry and drug discovery research [28,29]. These hybrid molecules may display dual activity but do not necessarily act on the same biological target [30-34].

In this work, four chalcone-triclosan, chromone-triclosan, and coumarin-triclosan hybrids (Schemes 1 and 2) were synthesized and their cytotoxic and leishmanicidal activities determined in the search for new therapeutic alternatives for the treatment of leishmaniasis.

\section{Results and Discussion}

\subsection{Chemistry}

Triclosan-chalcone hybrids 7-10 were obtained via microwave assisted Williamson etherification [35] between bromoalkyltriclosan 2-5 and 3,4-dimethoxy-4'-hydroxychalcone (6). Reaction yields ranged between $35 \%$ and $60 \%$. Chalcone 6 was prepared using a previously described method [36] (Scheme 1).

Scheme 1. Synthetic pathway to triclosan-chalcone hybrids.
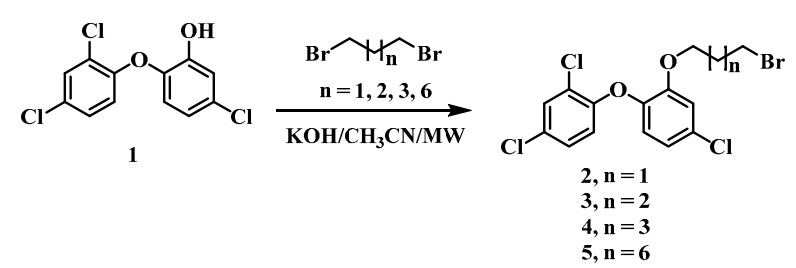

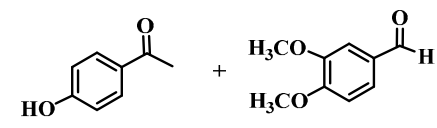

Silica sulfuric acid $\downarrow$ solvent free, $80^{\circ} \mathrm{C}$

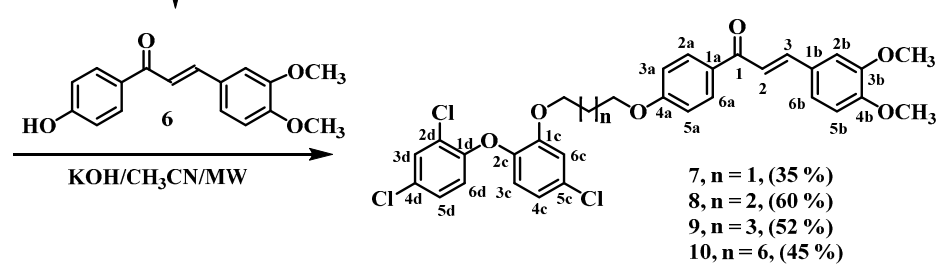

Scheme 2. Synthetic pathway to triclosan-coumarin and triclosan-chromone hybrids.
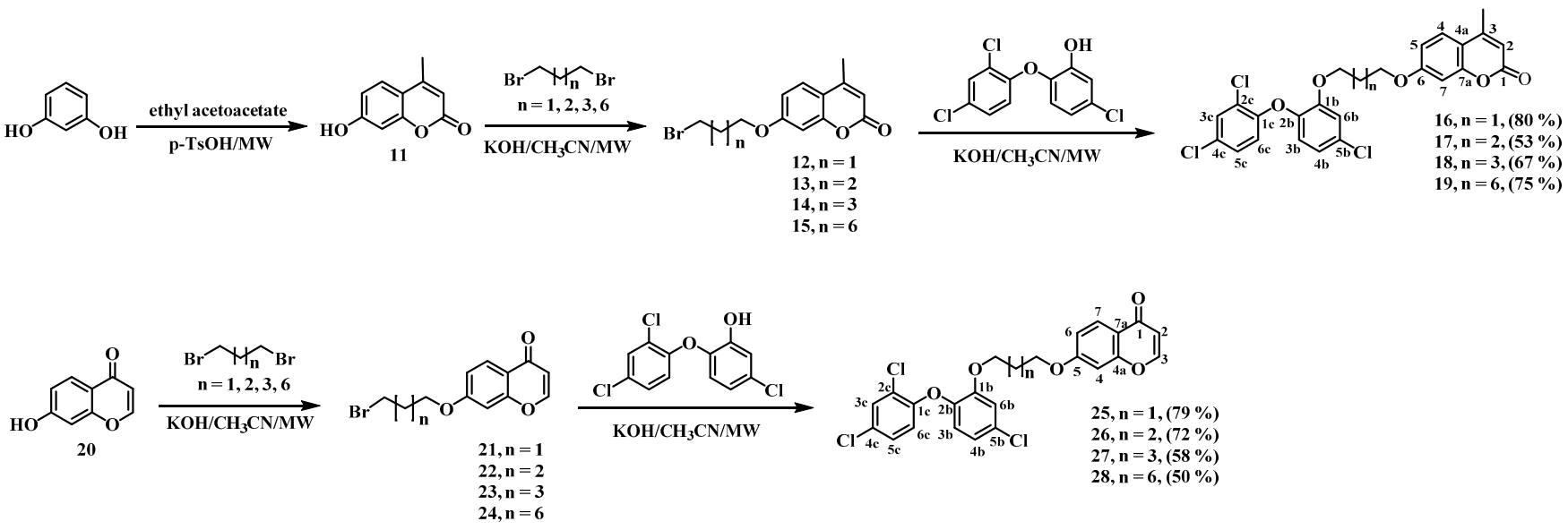
Triclosan-coumarin and triclosan-chromone hybrids were obtained following the same synthetic strategy (Scheme 2). Initially, 7-hydroxy-4-methylcoumarin (11, obtained by microwave assisted Pechmann reaction between resorcinol and ethyl acetoacetate [37]) or commercially available 7-hydroxychromone (20) were treated with potassium hydroxide and 1, $\omega$-dibromoalkanes $(\omega=3,4,5,8)$ to obtain the respective bromoalkyl derivatives in yields similar to previous reports $[9,38,39]$ but in significantly shorter times. These compounds were coupled with triclosan to produce compounds 16-19 and $\mathbf{2 5 - 2 8}$ in 50\%-80\% yields. Remarkably, low yields were obtained when bromoalkyltriclosan analogs were used as tactical variants.

\subsection{Antileishmanial and Cytotoxic Activities}

The leishmanicidal activity and cytotoxicity of the synthesized compounds was evaluated following previously reported method [40,41]. Leishmanicidal activity was reported as percentage of inhibition at $20 \mu \mathrm{g} / \mathrm{mL}$ and $50 \%$ effective concentration $\left(\mathrm{EC}_{50}\right)$ values. On the other hand, cytotoxicity was reported as $50 \%$ lethal concentration $\left(\mathrm{LC}_{50}\right)$ values. Results are summarized in Table 1.

Table 1. In vitro toxicity and anti-Leishmania activity of triclosan-chalcone, triclosan-chromone and triclosan-coumarin hybrids.

\begin{tabular}{|c|c|c|c|c|}
\hline \multirow{2}{*}{ Compound } & \multirow{2}{*}{$\begin{array}{c}\text { Cytotoxicity } \\
\mathrm{LC}_{50}(\mu \mathrm{g} / \mathrm{mL}, \boldsymbol{\mu M})^{\mathrm{a}}\end{array}$} & \multicolumn{2}{|c|}{ Leishmanicidal activity } & \multirow{2}{*}{$S I^{d}$} \\
\hline & & $\%$ Inhibition $^{b}$ & $\mathrm{EC}_{50}(\mu \mathrm{g} / \mathrm{mL}, \mu \mathrm{M})^{\mathrm{c}}$ & \\
\hline 7 & $>200.0,>326.7$ & $67.4 \pm 17.2$ & $9.4 \pm 1.3,15.4$ & $>21.3$ \\
\hline 8 & $>200.0,>319.4$ & $67.8 \pm 19.0$ & $10.2 \pm 1.8,16.3$ & $>19.6$ \\
\hline 9 & $>200.0,>311,4$ & $69.5 \pm 8.6$ & $13.5 \pm 3.6,21.1$ & $>14.8$ \\
\hline 10 & $>200.0,>293.2$ & $23.3 \pm 5.2$ & $\mathrm{NE}^{\mathrm{e}}$ & $\mathrm{NC}^{\mathrm{f}}$ \\
\hline 16 & $>200.0,>396.8$ & $34.0 \pm 0.3$ & $\mathrm{NE}^{\mathrm{e}}$ & $\mathrm{NC}^{\mathrm{f}}$ \\
\hline 17 & $>200.0,>386.1$ & $57.1 \pm 11.5$ & $27.5 \pm 0.8,53.1$ & $>7.3$ \\
\hline 18 & $>200.0,>375.9$ & 0.0 & $\mathrm{NE}^{\mathrm{e}}$ & $\mathrm{NC}^{\mathrm{f}}$ \\
\hline 19 & $>200.0,>348.4$ & 0.0 & $\mathrm{NE}^{\mathrm{e}}$ & $\mathrm{NC}^{\mathrm{f}}$ \\
\hline 25 & $6.4 \pm 0.8,13.1$ & $94.4 \pm 2.9$ & $2.7 \pm 0.4,5.5$ & 2.4 \\
\hline 26 & $15.8 \pm 4.3,31.3$ & $91.0 \pm 9.6$ & $7.5 \pm 0.2,14.9$ & 2.1 \\
\hline 27 & $25.8 \pm 4.2,49.8$ & $75.5 \pm 1.5$ & $16.0 \pm 1.0,30.9$ & 1.6 \\
\hline 28 & $80.0 \pm 18.5,142.8$ & $28.4 \pm 2.1$ & $\mathrm{NE}^{\mathrm{e}}$ & $\mathrm{NC}^{\mathrm{f}}$ \\
\hline Triclosan & $22.1 \pm 3.1,76.3$ & $61.8 \pm 5.5$ & $18.3 \pm 2.01,63.2$ & 1.3 \\
\hline 3,4-Dimethoxy-4'-hydroxychalcone (6) & $13.9 \pm 1.4,48.9$ & $52.4 \pm 6.5$ & $20.03 \pm 1.4,70.5$ & 0.7 \\
\hline 7-Hydroxychromone $(\mathbf{2 0})$ & $>200.0,>1234.6$ & $14.8 \pm 0.9$ & $\mathrm{NE}^{\mathrm{e}}$ & $\mathrm{NC}^{\mathrm{f}}$ \\
\hline 7-Hydroxy-4-methylcoumarin (11) & $98.2 \pm 6.7,557.4$ & $15.3 \pm 0.1$ & $\mathrm{NE}^{\mathrm{e}}$ & $\mathrm{NC}^{\mathrm{f}}$ \\
\hline$S b(V)^{\mathrm{g}}$ & $495.9+55.6$ & $79.4 \pm 2.1^{h}$ & $6.3+0.9$ & 78.7 \\
\hline Amphotericin B & $42.1 \pm 2.0,45.6$ & $69.1 \pm 1.3^{\mathrm{i}}$ & $0.06 \pm 0.01,0.1$ & 592 \\
\hline
\end{tabular}

\pm Standard deviation; ${ }^{\mathrm{a}} \mathrm{LC}_{50}$ : Lethal Concentration $50 ;{ }^{\mathrm{b}} \%$ Inhibition at $20 \mu \mathrm{g} / \mathrm{mL} ;{ }^{\mathrm{c}} \mathrm{EC}_{50}$ : Effective Concentration $50 ;{ }^{\mathrm{d}}$ IS: Selectivity Index: $=\mathrm{LC}_{50} / \mathrm{EC}_{50}$; ${ }^{\mathrm{e}} \mathrm{NE}$ : Not evaluated because inhibition was below $50 \%$ at $20 \mu \mathrm{g} / \mathrm{mL} ;{ }^{\mathrm{f}} \mathrm{NC}$ : Not calculated because $\mathrm{EC}_{50}$ wasn't determined; ${ }^{\mathrm{g}} \mathrm{SbV}$ : pentavalent antimonial meglumine antimoniate; ${ }^{\mathrm{h}}$ Dose employed: $10 \mu \mathrm{g} / \mathrm{mL} ;{ }^{i}$ Dose employed: $0.05 \mu \mathrm{g} / \mathrm{mL}$.

According to the results shown in Table 1, triclosan, chalcone and compounds 7-9, 17 and 25-27 showed activity against intracellular amastigotes of $L$. $(V)$ panamensis with more than $50 \%$ inhibition 
at $20 \mu \mathrm{g} / \mathrm{mL}$. The most active compounds were 25-27, with inhibitions of $94.4 \%, 91.0 \%$ and $75.5 \%$, respectively. Compounds 7-9 and $\mathbf{1 7}$ showed a moderate activity with inhibitions of $67.4 \%, 67.8 \%$, $69.5 \%$ and $57.1 \%$, respectively. On the other hand, high toxicity was measured for compounds 25-27, with $\mathrm{LC}_{50}<26 \mu \mathrm{g} / \mathrm{mL}$. Lower toxic activity was obtained for compounds 7-9 and 17 $\left(\mathrm{LC}_{50}>200.0 \mu \mathrm{g} / \mathrm{mL}\right)$. Weak to negligible leishmanicidal activity and no toxicity were detected for compounds 10, 16, 18, and 19 (inhibition $<50 \%$ at $20 \mu \mathrm{g} / \mathrm{mL}$ and $\mathrm{LC}_{50}$ higher than $200 \mu \mathrm{g} / \mathrm{mL}$, respectively). Compound $\mathbf{2 8}$ displayed very low activity and moderate cytotoxicity with values of $28.4 \%$ and $80.0 \mu \mathrm{g} / \mathrm{mL}$, respectively.

The effective concentration against the intracellular forms of $L .(V)$ panamensis was also measured for those compounds showing percentages of inhibition higher than $50 \%$ at $20 \mu \mathrm{g} / \mathrm{mL}$ (Table 1). Thus, compounds 10, 16, 18, 19 and 28 were not evaluated. The most active compounds for intracellular parasites were 25,26 and 7 with $\mathrm{EC}_{50}$ of $2.7,7.5$ and $9.4 \mu \mathrm{g} / \mathrm{mL}$, respectively, followed by compounds 8, 9 and 27 with $\mathrm{EC}_{50}$ values of 10.2, 13.5 and $16.0 \mu \mathrm{g} / \mathrm{mL}$, respectively (Table 1). All compounds showed leishmanicidal activity higher than cytotoxicity and therefore, selectivity indexes higher than 1. The best SI's were observed for compounds 7-9 and $\mathbf{1 7}$ with values higher than of 21.3, 19.6, 14.8 and 7.3, respectively. Although compound 25 showed better activity than meglumine antimoniate, its SI is affected by the high cytotoxicity.

On a structure-activity relationship basis, it is interesting to note the synergistic effect of the parent subunits in the hybrids in comparison with the unlinked cases. For example, chalcone 6 and triclosan are less potent and more cytotoxic individually than their hybrids 7-9. This phenomenon can also be observed in compounds 25-27 in which an increase in activity is evident in the hybrids at the expense of cytotoxicity compared to the individual units. The length of the alkyl linker also plays a pivotal role, with an inverse correlation between increased length and activity for the evaluated cases.

One possible mechanisms of action for these compounds may be formulated in terms of conjugated addition of nucleophilic amino acid residues present in biomolecules of the natural receptors, in a Michael type mechanism. This mechanism has been reported for other $\alpha, \beta$-unsaturated compounds such as lactones and cinnamic acid esters [42-44]. In this regard, the low reactivity shown by triclosan-coumarin hybrids could be rationalized in terms of steric hindrance and electronic deactivation caused by the methyl group at the $\beta$-position.

\section{Experimental Section}

\subsection{Chemical Synthesis}

\subsubsection{General Remarks}

The syntheses were carried out in a MW domestic oven adapted for the use of a reflux condenser and magnetic stirrer, at constant power $(400 \mathrm{~W})$. NMR spectra were recorded as $\mathrm{CDCl}_{3}$ solutions on an AMX 300 instrument (Bruker, Billerica, MA, USA) operating at $300 \mathrm{MHz}$ for $1 \mathrm{H}$ and $75 \mathrm{MHz}$ for ${ }^{1} \mathrm{C}$. Chemical shifts $(\delta)$ are expressed in ppm with the solvent peak as reference and TMS as an internal standard; coupling constants $(\mathrm{J})$ are given in Hertz $(\mathrm{Hz})$. High resolution mass spectra were recorded using electrospray ionization mass spectrometry (ESI-MS). A QTOF Premier instrument with an orthogonal Z-spray-electrospray interface (Waters, Manchester, UK) was used operating in the 
$\mathrm{W}$-mode. The drying and cone gas was nitrogen set to flow rates of 300 and $30 \mathrm{~L} / \mathrm{h}$, respectively. Methanol sample solutions ( $c a .1 \times 10^{-5} \mathrm{M}$ ) were directly introduced to the ESI spectrometer at a flow rate of $10 \mu \mathrm{L} / \mathrm{min}$. A capillary voltage of $3.5 \mathrm{kV}$ was used in the positive scan mode, and the cone voltage set to $U \mathrm{c}=10 \mathrm{~V}$. For the accurate mass measurements, a $2 \mathrm{mg} / \mathrm{L}$ standard solution of leucine enkephalin was introduced via the lock spray needle at a cone voltage set to $85 \mathrm{~V}$ and a flow rate of $30 \mu \mathrm{L} / \mathrm{min}$. IR spectra were recorded on a Spectrum RX I FT-IR system (Perkin-Elmer, Waltham, MA, USA) in $\mathrm{KBr}$ disks. Elemental analysis were recorded on TruSpec Micro Series equipment (LECO Corporation, St. Joseph, MI, USA). Commercially available reagents were used as received. Silica gel 60 (0.063-0.200 mesh, Merck, Whitehouse Station, NJ, USA) was used for column chromatography, and precoated silica gel plates (Merck 60 F254 $0.2 \mathrm{~mm}$ ) were used for thin layer chromatography (TLC).

\subsubsection{General Procedure for the Synthesis of Bromoalkyl Derivatives}

Triclosan, chromone or coumarin ( $1 \mathrm{mmol}, 1$ eq.), potassium hydroxide (3 eq.) and acetonitrile $(10 \mathrm{~mL})$, were placed in a $50 \mathrm{~mL}$ flat-bottomed flask equipped with a magnetic stirring bar. The mixture was stirred and heated to reflux for a period of $5 \mathrm{~min}$, under microwave irradiation. Then, 1, $\omega$-dibromoalkane (1.1 eq.) was added to the reaction mixture which was refluxed for $30 \mathrm{~min}$. The crude reaction mixture was concentrated on a rotatory evaporator, and the residue was purified by column chromatography over silica gel eluting with hexane and a mixture of hexane-ethyl acetate (9:1 ratio) to obtain the bromoalkyl derivatives in yields ranging between $60 \%-85 \%$. Monitoring of the reaction progress and product purification was carried out by TLC.

7-[(8-Bromooctyl)oxy]-4-methyl-2H-chromen-2-one (15). Yield 60\% (1.02 mmol, $375.3 \mathrm{mg})$; pale yellow oil; IR $\left(\mathrm{cm}^{-1}\right): v_{\max } 2933(\mathrm{C}-\mathrm{H}), 1737(\mathrm{C}=\mathrm{O}), 1612(\mathrm{C}=\mathrm{C}), 1463\left(\mathrm{C}=\mathrm{C}_{\mathrm{Ar}}\right), 1261(\mathrm{C}-\mathrm{O}-\mathrm{C}), 1199$ $((\mathrm{C}=\mathrm{O})-\mathrm{O}), 842\left(\mathrm{C}-\mathrm{H}_{\mathrm{Ar}}\right) ;{ }^{1} \mathrm{H}-\mathrm{NMR}\left(\mathrm{CDCl}_{3}\right): \delta 1.35-1.46(4 \mathrm{H}, \mathrm{m}), 1.46-1.58(4 \mathrm{H}, \mathrm{m}), 1.78-1.97(4 \mathrm{H}$, m), $2.43\left(\mathrm{~S}, \mathrm{CH}_{3}\right), 3.45\left(\mathrm{CH}_{2} \mathrm{Br}, \mathrm{t}, J=6.9 \mathrm{~Hz}\right), 4.05\left(\mathrm{CH}_{2} \mathrm{O}-, \mathrm{t}, J=6.6 \mathrm{~Hz}\right), 6.16(\mathrm{H} 2, \mathrm{~s}), 6.83\left(\mathrm{H}_{7}, \mathrm{~d}\right.$, $J=2.4 \mathrm{~Hz}), 6.88\left(\mathrm{H}_{5}, \mathrm{dd}, J=8.8,2.4 \mathrm{~Hz}\right), 7.52\left(\mathrm{H}_{4}, \mathrm{~d}, J=8.8 \mathrm{~Hz}\right) ;{ }^{13} \mathrm{C}-\mathrm{NMR}\left(\mathrm{CDCl}_{3}\right): \delta 18.67\left(\mathrm{CH}_{3}\right)$, $25.88\left(\mathrm{CH}_{2}\right), 28.08\left(\mathrm{CH}_{2}\right), 28.66\left(\mathrm{CH}_{2}\right), 28.96\left(\mathrm{CH}_{2}\right), 29.14\left(\mathrm{CH}_{2}\right), 32.77\left(\mathrm{CH}_{2}\right), 33.95\left(\mathrm{CH}_{2} \mathrm{Br}\right), 68.65$ $\left(\mathrm{CH}_{2} \mathrm{O}\right), 101.37\left(\mathrm{C}_{7}\right), 111.84\left(\mathrm{C}_{5}\right), 112.68\left(\mathrm{C}_{2}\right), 113.45\left(\mathrm{C}_{4 \mathrm{a}}\right), 125.49\left(\mathrm{C}_{4}\right), 152.61\left(\mathrm{C}_{7 \mathrm{a}}\right), 155.33\left(\mathrm{C}_{3}\right)$, $161.38\left(\mathrm{C}_{6}\right), 162.23(\mathrm{C}=\mathrm{O})$.

7-(4-Bromobutoxy)-4H-chromen-4-one (22). Yield 82\% (1.52 mmol, $450.78 \mathrm{mg})$; pale yellow oil; IR $\left(\mathrm{cm}^{-1}\right)$ : $v_{\max } 2953(\mathrm{C}-\mathrm{H}), 1639(\mathrm{C}=\mathrm{O}), 1595(\mathrm{C}=\mathrm{C}), 1438\left(\mathrm{C}=\mathrm{C}_{\mathrm{Ar}}\right), 1265(\mathrm{C}-\mathrm{O}-\mathrm{C}), 856\left(\mathrm{C}-\mathrm{H}_{\mathrm{Ar}}\right)$; ${ }^{1} \mathrm{H}-\mathrm{NMR}\left(\mathrm{CDCl}_{3}\right): \delta 1.98-2.09(2 \mathrm{H}, \mathrm{m}), 2.09-2.18(2 \mathrm{H}, \mathrm{m}), 3.53\left(\mathrm{CH}_{2} \mathrm{Br}, \mathrm{t}, J=6.5 \mathrm{~Hz}\right), 4.12\left(\mathrm{CH}_{2} \mathrm{O}, \mathrm{t}\right.$, $J=6.0 \mathrm{~Hz}), 6.31\left(\mathrm{H}_{2}, \mathrm{~d}, J=6.1 \mathrm{~Hz}\right), 6.86\left(\mathrm{H}_{4}, \mathrm{~d}, J=2.3 \mathrm{~Hz}\right), 6.99\left(\mathrm{H}_{6}, \mathrm{dd}, J=9.0,2.2 \mathrm{~Hz}\right), 7.81\left(\mathrm{H}_{3}, \mathrm{~d}\right.$, $J=6.0 \mathrm{~Hz}), 8.14\left(\mathrm{H}_{7}, \mathrm{~d}, J=9.0 \mathrm{~Hz}\right) ;{ }^{13} \mathrm{C}-\mathrm{NMR}\left(\mathrm{CDCl}_{3}\right): \delta 27.63\left(\mathrm{CH}_{2}\right), 29.29\left(\mathrm{CH}_{2}\right), 33.17\left(\mathrm{CH}_{2} \mathrm{Br}\right)$, $67.58\left(\mathrm{CH}_{2} \mathrm{O}\right), 100.93\left(\mathrm{C}_{4}\right), 112.97\left(\mathrm{C}_{6}\right), 114.75\left(\mathrm{C}_{2}\right), 118.83\left(\mathrm{C}_{7 \mathrm{a}}\right), 127.26\left(\mathrm{C}_{7}\right), 154.88\left(\mathrm{C}_{3}\right), 158.24$ $\left(\mathrm{C}_{4 \mathrm{a}}\right), 163.35\left(\mathrm{C}_{5}\right), 177.02(\mathrm{C}=\mathrm{O})$.

7-[(5-Bromopentyl)oxy]-4H-chromen-4-one (23). Yield 85\% (1.57 mmol, $489.3 \mathrm{mg})$; pale yellow oil; IR $\left(\mathrm{cm}^{-1}\right)$ : $v_{\max } 2929(\mathrm{C}-\mathrm{H}), 1649(\mathrm{C}=\mathrm{O}), 1595(\mathrm{C}=\mathrm{C}), 1439\left(\mathrm{C}=\mathrm{C}_{\mathrm{Ar}}\right), 1267$ (C-O-C), 856 $\left(\mathrm{C}-\mathrm{H}_{\mathrm{Ar}}\right) ;{ }^{1} \mathrm{H}-\mathrm{NMR}\left(\mathrm{CDCl}_{3}\right): \delta 1.61-1.74(2 \mathrm{H}, \mathrm{m}), 1.83-1.93(2 \mathrm{H}, \mathrm{m}), 1.93-2.04(2 \mathrm{H}, \mathrm{m}), 3.48\left(\mathrm{CH}_{2} \mathrm{Br}\right.$, 
$\mathrm{t}, J=6.7 \mathrm{~Hz}), 4.08\left(\mathrm{CH}_{2} \mathrm{O}, \mathrm{t}, J=6.3 \mathrm{~Hz}\right), 6.30\left(\mathrm{H}_{2}, \mathrm{~d}, J=6.1 \mathrm{~Hz}\right), 6.84\left(\mathrm{H}_{4}, \mathrm{~d}, J=2.3 \mathrm{~Hz}\right), 6.98\left(\mathrm{H}_{6}\right.$, $\mathrm{dd}, J=8.9,2.3 \mathrm{~Hz}), 7.80\left(\mathrm{H}_{3}, \mathrm{~d}, J=6.0 \mathrm{~Hz}\right), 8.12\left(\mathrm{H}_{7}, \mathrm{~d}, J=9.0 \mathrm{~Hz}\right) ;{ }^{13} \mathrm{C}-\mathrm{NMR}\left(\mathrm{CDCl}_{3}\right): \delta 24.74$ $\left(\mathrm{CH}_{2}\right), 28.17\left(\mathrm{CH}_{2}\right), 32.37\left(\mathrm{CH}_{2}\right), 33.51\left(\mathrm{CH}_{2} \mathrm{Br}\right), 68.29\left(\mathrm{CH}_{2} \mathrm{O}\right), 100.88\left(\mathrm{C}_{4}\right), 112.94\left(\mathrm{C}_{6}\right), 114.81$ $\left(\mathrm{C}_{2}\right), 118.72\left(\mathrm{C}_{7 \mathrm{a}}\right), 127.18\left(\mathrm{C}_{7}\right), 154.89\left(\mathrm{C}_{3}\right), 158.25\left(\mathrm{C}_{4 \mathrm{a}}\right), 163.49\left(\mathrm{C}_{5}\right), 177.05(\mathrm{C}=\mathrm{O})$.

7-[(8-Bromooctyl)oxy]-4H-chromen-4-one (24). Yield 71\% (1.31 mmol, $464 \mathrm{mg})$; yellow oil; IR $\left(\mathrm{cm}^{-1}\right)$ : $v_{\max } 2939(\mathrm{C}-\mathrm{H}), 1653(\mathrm{C}=\mathrm{O}), 1596(\mathrm{C}=\mathrm{C}), 1444\left(\mathrm{C}=\mathrm{C}_{\mathrm{Ar}}\right), 1227(\mathrm{C}-\mathrm{O}-\mathrm{C}), 856\left(\mathrm{C}-\mathrm{H}_{\mathrm{Ar}}\right)$; ${ }^{1} \mathrm{H}-\mathrm{NMR}\left(\mathrm{CDCl}_{3}\right): \delta 1.34-1.46(4 \mathrm{H}, \mathrm{m}), 1.46-1.60(4 \mathrm{H}, \mathrm{m}), 1.77-1.97(4 \mathrm{H}, \mathrm{m}), 3.45\left(\mathrm{CH}_{2} \mathrm{Br}, \mathrm{t}\right.$, $J=6.8 \mathrm{~Hz}), 4.08\left(\mathrm{CH}_{2} \mathrm{O}, \mathrm{t}, J=6.5 \mathrm{~Hz}\right), 6.31\left(\mathrm{H}_{2}, \mathrm{~d}, J=6.1 \mathrm{~Hz}\right), 6.86\left(\mathrm{H}_{4}, \mathrm{~d}, J=2.3 \mathrm{~Hz}\right), 7.01\left(\mathrm{H}_{6}, \mathrm{dd}\right.$, $J=8.9,2.3 \mathrm{~Hz}), 7.81\left(\mathrm{H}_{3}, \mathrm{~d}, J=6.0 \mathrm{~Hz}\right), 8.14\left(\mathrm{H}_{7}, \mathrm{~d}, J=8.9 \mathrm{~Hz}\right) ;{ }^{13} \mathrm{C}-\mathrm{NMR}\left(\mathrm{CDCl}_{3}\right): \delta 25.88\left(\mathrm{CH}_{2}\right)$, $28.07\left(\mathrm{CH}_{2}\right), 28.66\left(\mathrm{CH}_{2}\right), 28.93\left(\mathrm{CH}_{2}\right), 29.13\left(\mathrm{CH}_{2}\right), 32.76\left(\mathrm{CH}_{2}\right), 33.95\left(\mathrm{CH}_{2} \mathrm{Br}\right), 68.65\left(\mathrm{CH}_{2} \mathrm{O}\right)$, $100.88\left(\mathrm{C}_{4}\right), 112.92\left(\mathrm{C}_{6}\right), 114.88\left(\mathrm{C}_{2}\right), 118.64\left(\mathrm{C}_{7 \mathrm{a}}\right), 127.17\left(\mathrm{C}_{7}\right), 154.86\left(\mathrm{C}_{3}\right), 158.31\left(\mathrm{C}_{4 \mathrm{a}}\right), 163.70$ $\left(\mathrm{C}_{5}\right), 177.11(\mathrm{C}=\mathrm{O})$.

\subsubsection{General Procedure for the Synthesis of Triclosan-Chalcone Hybrids}

Chalcone (1.1 eq.), potassium hydroxide (2 eq.) and acetonitrile $(10 \mathrm{~mL})$, were placed in a $50 \mathrm{~mL}$ flat-bottomed flask equipped with a magnetic stirring bar. The mixture was stirred and heated to reflux for a period of $5 \mathrm{~min}$, under microwave irradiation. Then, bromoalkyltriclosan (100 mg, 1 eq.) was added to the reaction mixture which was then refluxed for $30 \mathrm{~min}$. The crude reaction mixture was concentrated on a rotatory evaporator, and the residue was purified by column chromatography over silica gel eluting with hexane-ethyl acetate (9:1 ratio) to obtain the triclosan-chalcone hybrids in yields between 35\%-60\%. Monitoring of the reaction progress and product purification was carried out by TLC.

(2E)-1-(4-\{3-[5-Chloro-2-(2,4-dichlorophenoxy)phenoxy]propoxy\}phenyl)-3-(3,4-dimethoxyphenyl) prop-2-en-1-one (7). Yield 35\% (0.085 mmol, $52 \mathrm{mg})$; yellow solid, M.p. $129-130{ }^{\circ} \mathrm{C}$; IR $\left(\mathrm{cm}^{-1}\right): v_{\max }$ $2935(\mathrm{C}-\mathrm{H}), 1601(\mathrm{C}=\mathrm{O}), 1512(\mathrm{C}=\mathrm{C}), 1471\left(\mathrm{C}=\mathrm{C}_{\mathrm{Ar}}\right), 1265(\mathrm{C}-\mathrm{O}-\mathrm{C}), 1160((\mathrm{C}=\mathrm{O})-\mathrm{O}), 800\left(\mathrm{C}-\mathrm{H}_{\mathrm{Ar}}\right)$, $742(\mathrm{C}-\mathrm{Cl}) ;{ }^{1} \mathrm{H}-\mathrm{NMR}\left(\mathrm{CDCl}_{3}\right): \delta 2.13-2.25(2 \mathrm{H}, \mathrm{m}), 3.96\left(\mathrm{CH}_{2} \mathrm{O}, \mathrm{t}, J=6.1 \mathrm{~Hz}\right), 3.98\left(\mathrm{OCH}_{3}, \mathrm{~s}\right), 4.01$ $\left(\mathrm{OCH}_{3}, \mathrm{~s}\right), 4.18\left(\mathrm{CH}_{2} \mathrm{O}, \mathrm{t}, J=5.8 \mathrm{~Hz}\right), 6.62\left(\mathrm{H}_{3 \mathrm{c}}, \mathrm{d}, J=8.8 \mathrm{~Hz}\right), 6.90\left(\mathrm{H}_{6 \mathrm{~d}}, \mathrm{~d}, J=8.8 \mathrm{~Hz}\right), 6.95\left(\mathrm{H}_{3 \mathrm{a}}, \mathrm{H}_{5 \mathrm{a}}\right.$, $\mathrm{d}, J=8.4 \mathrm{~Hz}), 6.99\left(\mathrm{H}_{4 \mathrm{c}}, \mathrm{dd}, J=6.5,2.5\right), 6.99-7.03\left(\mathrm{H}_{5 \mathrm{~b}}, \mathrm{H}_{6 \mathrm{~b}}, \mathrm{~m}\right), 7.06\left(\mathrm{H}_{6 \mathrm{c}}, \mathrm{d}, J=2.5 \mathrm{~Hz}\right), 7.21\left(\mathrm{H}_{2 \mathrm{~b}}\right.$, $\mathrm{d}, \mathrm{J}=1.8 \mathrm{~Hz}), 7.29\left(\mathrm{H}_{5 \mathrm{~d}}, \mathrm{dd}, J=8.5,1.8 \mathrm{~Hz}\right), 7.45\left(\mathrm{H}_{3 \mathrm{~d}}, \mathrm{~d}, J=2.5 \mathrm{~Hz}\right), 7.46\left(\mathrm{H}_{2}, \mathrm{~d}, J=15.5 \mathrm{~Hz}\right), 7.81$ $\left(\mathrm{H}_{3}, \mathrm{~d}, J=15.5 \mathrm{~Hz}\right), 8.06\left(\mathrm{H}_{2 \mathrm{a}}, \mathrm{H}_{6 \mathrm{a}}, \mathrm{d}, J=8.9 \mathrm{~Hz}\right) ;{ }^{13} \mathrm{C}-\mathrm{NMR}\left(\mathrm{CDCl}_{3}\right): \delta 28.91\left(\mathrm{CH}_{2}\right), 56.0\left(2 \mathrm{OCH}_{3}\right)$, $63.85\left(\mathrm{CH}_{2} \mathrm{O}\right), 65.10\left(\mathrm{CH}_{2} \mathrm{O}\right), 110.10\left(\mathrm{C}_{2 \mathrm{~b}}\right), 111.20\left(\mathrm{C}_{5 \mathrm{~b}}\right), 114.20\left(\mathrm{C}_{3 \mathrm{a}}, \mathrm{C}_{5 \mathrm{a}}\right), 114.70\left(\mathrm{C}_{6 \mathrm{c}}\right), 117.40\left(\mathrm{C}_{3 \mathrm{c}}\right)$, $119.90\left(\mathrm{C}_{6 \mathrm{~b}}\right), 121.30\left(\mathrm{C}_{6 \mathrm{~d}}\right), 122.2\left(\mathrm{C}_{4 \mathrm{c}}\right), 122.60\left(\mathrm{C}_{2}\right), 123.0\left(\mathrm{C}_{2 \mathrm{~d}}\right), 124.10\left(\mathrm{C}_{1 \mathrm{~b}}\right), 127.70\left(\mathrm{C}_{5 \mathrm{~d}}\right), 128.10$ $\left(\mathrm{C}_{5 \mathrm{c}}\right), 130.20\left(\mathrm{C}_{4 \mathrm{~d}}\right), 130.80\left(\mathrm{C}_{2 \mathrm{a}}, \mathrm{C}_{6 \mathrm{a}}\right), 130.90\left(\mathrm{C}_{1 \mathrm{a}}\right), 131.4\left(\mathrm{C}_{3 \mathrm{~d}}\right), 142.70\left(\mathrm{C}_{3}\right), 144.20\left(\mathrm{C}_{2 \mathrm{c}}\right), 149.30\left(\mathrm{C}_{1 \mathrm{c}}\right)$, $150.80\left(\mathrm{C}_{3 \mathrm{~b}}\right), 151.30\left(\mathrm{C}_{1 \mathrm{~d}}\right), 152.60\left(\mathrm{C}_{4 \mathrm{~b}}\right), 162.40\left(\mathrm{C}_{4 \mathrm{a}}\right), 188.82(\mathrm{C}=\mathrm{O})$; EIMS: $m / z 613.0946[\mathrm{M}+\mathrm{H}]^{+}$, for $\mathrm{C}_{32} \mathrm{H}_{28} \mathrm{Cl}_{3} \mathrm{O}_{6}$ : 613.0951. Anal. Calc. for $\mathrm{C}_{32} \mathrm{H}_{27} \mathrm{Cl}_{3} \mathrm{O}_{6}$ : C 62.61, H 4.43. Found $\mathrm{C}$ 63.15, $\mathrm{H} 4.72$.

(2E)-1-(4-\{4-[5-Chloro-2-(2,4-dichlorophenoxy)phenoxy]butoxy\}phenyl)-3-(3,4-dimethoxyphenyl) prop-2-en-1-one (8). Yield 60\% (0.142 mmol, $89.8 \mathrm{mg})$; yellow solid, M.p. $103-105{ }^{\circ} \mathrm{C}$; IR $\left(\mathrm{cm}^{-1}\right)$ : $v_{\max } 2954(\mathrm{C}-\mathrm{H}), 1601(\mathrm{C}=\mathrm{O}), 1512(\mathrm{C}=\mathrm{C}), 1472\left(\mathrm{C}=\mathrm{C}_{\mathrm{Ar}}\right), 1262(\mathrm{C}-\mathrm{O}-\mathrm{C}), 1163((\mathrm{C}=\mathrm{O})-\mathrm{O}), 800$ $\left(\mathrm{C}-\mathrm{H}_{\mathrm{Ar}}\right), 794(\mathrm{C}-\mathrm{Cl}) ;{ }^{1} \mathrm{H}-\mathrm{NMR}\left(\mathrm{CDCl}_{3}\right): \delta 1.72-1.84(2 \mathrm{H}, \mathrm{m}), 1.84-1.97(2 \mathrm{H}, \mathrm{m}), 3.98\left(\mathrm{OCH}_{3}, \mathrm{~s}\right), 4.01$ $\left(\mathrm{OCH}_{3}, \mathrm{~s}\right), 4.05\left(2 \mathrm{CH}_{2} \mathrm{O}, \mathrm{t}, J=6.4 \mathrm{~Hz}\right), 6.68\left(\mathrm{H}_{3 \mathrm{c}}, \mathrm{d}, J=8.8 \mathrm{~Hz}\right), 6.92-7.05\left(\mathrm{H}_{6 \mathrm{c}}, \mathrm{H}_{3 \mathrm{a}}, \mathrm{H}_{5 \mathrm{a}}, \mathrm{H}_{5 \mathrm{~b}}, \mathrm{H}_{6 \mathrm{~b}}\right.$, 
$\left.\mathrm{H}_{6 \mathrm{~d}}\right), 7.12\left(\mathrm{H}_{4 \mathrm{c}}, \mathrm{dd}, J=8.8,2.5 \mathrm{~Hz}\right), 7.21\left(\mathrm{H}_{2 \mathrm{~b}}, \mathrm{~d}, J=1.7\right), 7.28\left(\mathrm{H}_{5 \mathrm{~d}}, \mathrm{dd}, J=8.3,1.6 \mathrm{~Hz}\right), 7.44\left(\mathrm{H}_{3 \mathrm{~d}}, \mathrm{~d}\right.$, $J=2.4 \mathrm{~Hz}), 7.45\left(\mathrm{H}_{2}, \mathrm{~d}, J=15.5 \mathrm{~Hz}\right), 7.81\left(\mathrm{H}_{3}, \mathrm{~d}, J=15.5 \mathrm{~Hz}\right), 8.06\left(\mathrm{H}_{2 \mathrm{a}}, \mathrm{H}_{6 \mathrm{a}}, \mathrm{d}, J=8.7 \mathrm{~Hz}\right)$; ${ }^{13} \mathrm{C}-\mathrm{NMR}\left(\mathrm{CDCl}_{3}\right): \delta 25.55\left(\mathrm{CH}_{2}\right), 25.64\left(\mathrm{CH}_{2}\right), 56.03\left(2 \mathrm{OCH}_{3}\right), 67.46\left(\mathrm{CH}_{2} \mathrm{O}\right), 68.58\left(\mathrm{CH}_{2} \mathrm{O}\right), 110.11$ $\left(\mathrm{C}_{2 \mathrm{~b}}\right), 111.15\left(\mathrm{C}_{5 \mathrm{~b}}\right), 114.24\left(\mathrm{C}_{3 \mathrm{a}}, \mathrm{C}_{5 \mathrm{a}}\right), 114.80\left(\mathrm{C}_{6 \mathrm{c}}\right), 117.80\left(\mathrm{C}_{3 \mathrm{c}}\right), 119.70\left(\mathrm{C}_{6 \mathrm{~b}}\right), 121.16\left(\mathrm{C}_{6 \mathrm{~d}}\right), 122.25$ $\left(\mathrm{C}_{4 \mathrm{c}}\right), 122.60\left(\mathrm{C}_{2}\right), 123.0\left(\mathrm{C}_{2 \mathrm{~d}}\right), 124.35\left(\mathrm{C}_{1 \mathrm{~b}}\right), 127.61\left(\mathrm{C}_{5 \mathrm{c}}\right), 127.83\left(\mathrm{C}_{2 \mathrm{c}}\right), 128.12\left(\mathrm{C}_{5 \mathrm{~d}}\right), 130.17\left(\mathrm{C}_{4 \mathrm{~d}}\right)$, $130.7\left(\mathrm{C}_{3 \mathrm{~d}}\right), 130.76\left(\mathrm{C}_{2 \mathrm{a}}, \mathrm{C}_{6 \mathrm{a}}\right), 131.24\left(\mathrm{C}_{1 \mathrm{a}}\right), 143.01\left(\mathrm{C}_{3}\right), 144.35\left(\mathrm{C}_{2 \mathrm{c}}\right), 149.25\left(\mathrm{C}_{1 \mathrm{c}}\right), 150.85\left(\mathrm{C}_{3 \mathrm{~b}}\right)$, $151.30\left(\mathrm{C}_{1 \mathrm{~d}}\right), 152.60\left(\mathrm{C}_{4 \mathrm{~b}}\right), 162.68\left(\mathrm{C}_{4 \mathrm{a}}\right), 188.80(\mathrm{C}=\mathrm{O})$; EIMS: $m / z 627.1111[\mathrm{M}+\mathrm{H}]^{+}$, Calcd for $\mathrm{C}_{33} \mathrm{H}_{30} \mathrm{Cl}_{3} \mathrm{O}_{6}$ : 627.1108. Anal. Calc. for $\mathrm{C}_{33} \mathrm{H}_{29} \mathrm{Cl}_{3} \mathrm{O}_{6}$ : C 63.12, $\mathrm{H}$ 4.65. Found $\mathrm{C}$ 62.34, H 4.79.

(2E)-1-[4-(\{5-[5-Chloro-2-(2,4-dichlorophenoxy)phenoxy]pentyl\}oxy)phenyl]-3-(3,4-imethoxyphenyl) prop-2-en-1-one (9). Yield 52\% (0.119 mmol, $76 \mathrm{mg})$; yellow solid, M.p. $117-120{ }^{\circ} \mathrm{C}$; IR $\left(\mathrm{cm}^{-1}\right): v_{\max }$ $2949(\mathrm{C}-\mathrm{H}), 1603(\mathrm{C}=\mathrm{O}), 1510(\mathrm{C}=\mathrm{C}), 1472\left(\mathrm{C}=\mathrm{C}_{\mathrm{Ar}}\right), 1263(\mathrm{C}-\mathrm{O}-\mathrm{C}), 1159((\mathrm{C}=\mathrm{O})-\mathrm{O}), 862\left(\mathrm{C}-\mathrm{H}_{\mathrm{Ar}}\right)$, $742(\mathrm{C}-\mathrm{Cl}) ;{ }^{1} \mathrm{H}-\mathrm{NMR}\left(\mathrm{CDCl}_{3}\right): \delta 1.35-1.51(2 \mathrm{H}, \mathrm{m}), 1.69-1.86(4 \mathrm{H}, \mathrm{m}), 3.98\left(\mathrm{OCH}_{3}, \mathrm{~s}\right), 4.01\left(\mathrm{OCH}_{3}, \mathrm{~s}\right)$, $3.81-4.17(4 \mathrm{H}, \mathrm{m}), 6.66\left(\mathrm{H}_{3 \mathrm{c}}, \mathrm{d}, J=8.8 \mathrm{~Hz}\right), 6.94\left(\mathrm{H}_{4 \mathrm{c}}, \mathrm{dd}, J=8.3,1.4\right), 6.97-7.06\left(\mathrm{H}_{3 \mathrm{a}}, \mathrm{H}_{5 \mathrm{a}}, \mathrm{H}_{6 \mathrm{~d}}, \mathrm{H}_{5 \mathrm{~b}}\right.$, $\left.\mathrm{H}_{6 \mathrm{~b}}, \mathrm{H}_{6 \mathrm{c}}, \mathrm{m}\right), 7.08-7.15\left(\mathrm{H}_{5 \mathrm{~d}}, \mathrm{~m}\right), 7.21\left(\mathrm{H}_{2 \mathrm{~b}}, \mathrm{~d}, J=1.7\right), 7.29\left(\mathrm{H}_{5 \mathrm{~d}}, \mathrm{dd}, J=8.5,1.8 \mathrm{~Hz}\right), 7.45\left(\mathrm{H}_{3 \mathrm{~d}}, \mathrm{~d}\right.$, $J=2.0 \mathrm{~Hz}), 7.46\left(\mathrm{H}_{2}, \mathrm{~d}, J=15.5 \mathrm{~Hz}\right), 7.81\left(\mathrm{H}_{3}, \mathrm{~d}, J=15.5 \mathrm{~Hz}\right), 8.06\left(\mathrm{H}_{2 \mathrm{a}}, \mathrm{H}_{6 \mathrm{a}}, \mathrm{d}, J=8.8 \mathrm{~Hz}\right) ;{ }^{13} \mathrm{C}-\mathrm{NMR}$ $\left(\mathrm{CDCl}_{3}\right): \delta 22.45\left(\mathrm{CH}_{2}\right), 28.67\left(\mathrm{CH}_{2}\right), 28.73\left(\mathrm{CH}_{2}\right), 56.02\left(2 \mathrm{OCH}_{3}\right), 67.94\left(\mathrm{CH}_{2} \mathrm{O}\right), 68.83\left(\mathrm{CH}_{2} \mathrm{O}\right)$, $110.12\left(\mathrm{C}_{2 \mathrm{~b}}\right), 111.15\left(\mathrm{C}_{5 \mathrm{~b}}\right), 114.27\left(\mathrm{C}_{3 \mathrm{a}}, \mathrm{C}_{5 \mathrm{a}}\right), 114.71\left(\mathrm{C}_{6 \mathrm{c}}\right), 117.61\left(\mathrm{C}_{3 \mathrm{c}}\right), 119.89\left(\mathrm{C}_{6 \mathrm{~b}}\right), 121.05\left(\mathrm{C}_{6 \mathrm{~d}}\right)$, $122.41\left(\mathrm{C}_{4 \mathrm{c}}\right), 122.20\left(\mathrm{C}_{2}\right), 123.0\left(\mathrm{C}_{2 \mathrm{~d}}\right), 124.24\left(\mathrm{C}_{1 \mathrm{~b}}\right), 127.56\left(\mathrm{C}_{5 \mathrm{c}}\right), 127.63\left(\mathrm{C}_{2 \mathrm{c}}\right), 128.13\left(\mathrm{C}_{5 \mathrm{~d}}\right), 130.10$ $\left(\mathrm{C}_{4 \mathrm{~d}}\right), 130.76\left(\mathrm{C}_{1 \mathrm{a}}\right), 130.77\left(\mathrm{C}_{2 \mathrm{a}}, \mathrm{C}_{6 \mathrm{a}}\right), 131.20\left(\mathrm{C}_{3 \mathrm{~d}}\right), 142.84\left(\mathrm{C}_{3}\right), 144.12\left(\mathrm{C}_{2 \mathrm{c}}\right), 149.25\left(\mathrm{C}_{1 \mathrm{c}}\right), 151.0$ $\left(\mathrm{C}_{3 \mathrm{~b}}\right), 151.27\left(\mathrm{C}_{1 \mathrm{~d}}\right), 152.72\left(\mathrm{C}_{4 \mathrm{~b}}\right), 162.82\left(\mathrm{C}_{4 \mathrm{a}}\right), 188.82(\mathrm{C}=\mathrm{O})$; EIMS: $m / z 641.1265[\mathrm{M}+\mathrm{H}]^{+}$, Calcd for $\mathrm{C}_{34} \mathrm{H}_{32} \mathrm{Cl}_{3} \mathrm{O}_{6}$ : 641.1265. Anal. Calc. for $\mathrm{C}_{34} \mathrm{H}_{31} \mathrm{Cl}_{3} \mathrm{O}_{6}$ : C 63.61, H 4.87. Found $\mathrm{C}$ 61.36, $\mathrm{H} 4.84$.

(2E)-1-[4-(\{8-[5-Chloro-2-(2,4-dichlorophenoxy)phenoxy] octyl\}oxy)phenyl]-3-(3,4-dimethoxyphenyl) prop-2-en-1-one (10). Yield 45\% (0.094 mmol, $64 \mathrm{mg})$; yellow oil, IR ( $\left.\mathrm{cm}^{-1}\right): v_{\max } 2933(\mathrm{C}-\mathrm{H}), 1601$ $(\mathrm{C}=\mathrm{O}), 1512(\mathrm{C}=\mathrm{C}), 1471\left(\mathrm{C}=\mathrm{C}_{\mathrm{Ar}}\right), 1261 \quad(\mathrm{C}-\mathrm{O}-\mathrm{C}), 1166((\mathrm{C}=\mathrm{O})-\mathrm{O}), 804\left(\mathrm{C}-\mathrm{H}_{\mathrm{Ar}}\right), 740(\mathrm{C}-\mathrm{Cl})$; ${ }^{1} \mathrm{H}-\mathrm{NMR}\left(\mathrm{CDCl}_{3}\right): \delta$ 1.19-1.35 $(2 \mathrm{H}, \mathrm{m}), 1.37-1.58(6 \mathrm{H}, \mathrm{m}), 1.73-1.99(4 \mathrm{H}, \mathrm{m}), 3.46\left(\mathrm{CH}_{2} \mathrm{O}, \mathrm{t}\right.$, $J=6.8 \mathrm{~Hz}), 3.98\left(\mathrm{OCH}_{3}, \mathrm{~s}\right), 4.01\left(\mathrm{OCH}_{3}, \mathrm{~s}\right), 4.08\left(\mathrm{CH}_{2} \mathrm{O}, \mathrm{t}, J=6.5 \mathrm{~Hz}\right), 6.66\left(\mathrm{H}_{3 \mathrm{c}}, \mathrm{d}, J=8.8 \mathrm{~Hz}\right), 6.94$ $\left(\mathrm{H}_{6 \mathrm{~d}}, \mathrm{~d}, J=8.8 \mathrm{~Hz}\right), 6.97-7.05\left(\mathrm{H}_{3 \mathrm{a}}, \mathrm{H}_{5 \mathrm{a}}, \mathrm{H}_{5 \mathrm{~b}}, \mathrm{H}_{6 \mathrm{~b}}, \mathrm{H}_{6 \mathrm{c}}, \mathrm{m}\right), 7.11\left(\mathrm{H}_{4 \mathrm{c}}, \mathrm{dd}, J=8.8,2.5 \mathrm{~Hz}\right), 7.21\left(\mathrm{H}_{2 \mathrm{~b}}, \mathrm{~d}\right.$, $J=1.8 \mathrm{~Hz}), 7.28\left(\mathrm{H}_{5 \mathrm{~d}}, \mathrm{dd}, J=8.5,1.8 \mathrm{~Hz}\right), 7.45\left(\mathrm{H}_{3 \mathrm{~d}}, \mathrm{~d}, J=2.5 \mathrm{~Hz}\right), 7.46\left(\mathrm{H}_{2}, \mathrm{~d}, J=15.5 \mathrm{~Hz}\right), 7.81$ $\left(\mathrm{H}_{3}, \mathrm{~d}, J=15.5 \mathrm{~Hz}\right), 8.07\left(\mathrm{H}_{2 \mathrm{a}}, \mathrm{H}_{6 \mathrm{a}}, \mathrm{d}, J=8.8 \mathrm{~Hz}\right) ;{ }^{13} \mathrm{C}-\mathrm{NMR}\left(\mathrm{CDCl}_{3}\right): \delta 25.70\left(\mathrm{CH}_{2}\right), 25.93\left(\mathrm{CH}_{2}\right)$, $28.10\left(\mathrm{CH}_{2}\right), 28.70\left(\mathrm{CH}_{2}\right), 32.78\left(\mathrm{CH}_{2}\right), 34.03\left(\mathrm{CH}_{2}\right), 56.01\left(2 \mathrm{OCH}_{3}\right), 68.21\left(\mathrm{CH}_{2} \mathrm{O}\right), 69.0\left(\mathrm{CH}_{2} \mathrm{O}\right)$, $110.10\left(\mathrm{C}_{2 \mathrm{~b}}\right), 111.15\left(\mathrm{C}_{5 \mathrm{~b}}\right), 114.28\left(\mathrm{C}_{3 \mathrm{a}}, \mathrm{C}_{5 \mathrm{a}}\right), 114.62\left(\mathrm{C}_{6 \mathrm{c}}\right), 117.62\left(\mathrm{C}_{3 \mathrm{c}}\right), 119.9\left(\mathrm{C}_{6 \mathrm{~b}}\right), 120.85\left(\mathrm{C}_{6 \mathrm{~d}}\right)$, $122.37\left(\mathrm{C}_{4 \mathrm{c}}\right), 122.20\left(\mathrm{C}_{2}\right), 123.0\left(\mathrm{C}_{2 \mathrm{~d}}\right), 124.22\left(\mathrm{C}_{1 \mathrm{~b}}\right), 127.51\left(\mathrm{C}_{5 \mathrm{c}}\right), 127.61\left(\mathrm{C}_{2 \mathrm{c}}\right), 128.12\left(\mathrm{C}_{5 \mathrm{~d}}\right), 130.10$ $\left(\mathrm{C}_{4 \mathrm{~d}}\right), 130.76\left(\mathrm{C}_{1 \mathrm{a}}\right), 130.77\left(\mathrm{C}_{2 \mathrm{a}}, \mathrm{C}_{6 \mathrm{a}}\right), 131.12\left(\mathrm{C}_{3 \mathrm{~d}}\right), 142.83\left(\mathrm{C}_{3}\right), 144.10\left(\mathrm{C}_{2 \mathrm{c}}\right), 149.24\left(\mathrm{C}_{1 \mathrm{c}}\right), 151.1$ $\left(\mathrm{C}_{3 \mathrm{~b}}\right), 151.26\left(\mathrm{C}_{1 \mathrm{~d}}\right), 152.72\left(\mathrm{C}_{4 \mathrm{~b}}\right), 162.93\left(\mathrm{C}_{4 \mathrm{a}}\right), 188.81(\mathrm{C}=\mathrm{O})$; EIMS: $m / z 683.1736[\mathrm{M}+\mathrm{H}]^{+}$, Calcd for $\mathrm{C}_{37} \mathrm{H}_{38} \mathrm{Cl}_{3} \mathrm{O}_{6}$ : 683.1734. Anal. Calc. for $\mathrm{C}_{37} \mathrm{H}_{37} \mathrm{Cl}_{3} \mathrm{O}_{5}$ : C 64.97, $\mathrm{H}$ 5.45. Found $\mathrm{C}$ 64.07, $\mathrm{H}$ 6.04.

3.1.4. General Procedure for the Synthesis of Triclosan-Coumarin and Triclosan-Chromone Hybrids

Triclosan (1.1 eq.), potassium hydroxide (2 eq.) and acetonitrile $(10 \mathrm{~mL})$, were placed in a $50 \mathrm{~mL}$ flat-bottomed flask equipped with a magnetic stirring bar. The mixture was stirred and heated to reflux for a period of $5 \mathrm{~min}$ under microwave irradiation. Then, bromoalkylcoumarin or bromoalkylchromone 
(1 eq.) was added to the reaction mixture which was refluxed for $30 \mathrm{~min}$. The crude reaction mixture was concentrated on a rotatory evaporator, and the residue was purified by column chromatography over silica gel eluting with hexane-ethyl acetate (4:1 and then 3:2 ratio) to obtain the triclosan-chalcone hybrids in yields between $50 \%-80 \%$. Monitoring of the reaction progress and product purification was carried out by TLC.

7-\{3-[5-Chloro-2-(2,4-dichlorophenoxy)phenoxy]propoxy\}-4-methyl-2H-chromen-2-one (16). Yield 80\% (0.270 mmol, $136.8 \mathrm{mg})$; white solid, M.p. $139-141{ }^{\circ} \mathrm{C}$; IR $\left(\mathrm{cm}^{-1}\right): v_{\max } 2968(\mathrm{C}-\mathrm{H}), 1718(\mathrm{C}=\mathrm{O})$, $1610(\mathrm{C}=\mathrm{C}), 1477\left(\mathrm{C}=\mathrm{C}_{\mathrm{Ar}}\right), 1263(\mathrm{C}-\mathrm{O}-\mathrm{C}), 1144((\mathrm{C}=\mathrm{O})-\mathrm{O}), 847\left(\mathrm{C}-\mathrm{H}_{\mathrm{Ar}}\right), 740(\mathrm{C}-\mathrm{Cl})$; ${ }^{1} \mathrm{H}-\mathrm{NMR}$ $\left(\mathrm{CDCl}_{3}\right): \delta 1.14-1.25(2 \mathrm{H}, \mathrm{m}), 2.44\left(\mathrm{CH}_{3}, \mathrm{~s}\right), 3.98\left(\mathrm{CH}_{2} \mathrm{O}, \mathrm{t}, J=6.6 \mathrm{~Hz}\right), 4.18\left(\mathrm{CH}_{2} \mathrm{O}, \mathrm{t}, J=5.8 \mathrm{~Hz}\right)$, $6.18\left(\mathrm{H}_{2}, \mathrm{~s}\right), 6.61\left(\mathrm{H}_{3 \mathrm{~b}}, \mathrm{~d}, J=8.8 \mathrm{~Hz}\right), 6.76\left(\mathrm{H}_{7}, \mathrm{~d}, J=2.5 \mathrm{~Hz}\right), 6.79\left(\mathrm{H}_{5}, \mathrm{dd}, J=9.0,2.5 \mathrm{~Hz}\right), 6.96\left(\mathrm{H}_{6 \mathrm{~b}}, \mathrm{~d}\right.$, $J=2.5 \mathrm{~Hz}), 6.97-7.01\left(\mathrm{H}_{4 \mathrm{~b}}, \mathrm{H}_{6 \mathrm{c}}, \mathrm{m}\right), 7.03-7.08\left(\mathrm{H}_{5 \mathrm{c}}, \mathrm{m}\right), 7.43\left(\mathrm{H}_{3 \mathrm{c}}, \mathrm{d}, J=2.5 \mathrm{~Hz}\right), 7.51\left(\mathrm{H}_{4}, \mathrm{~d}, J=8.5 \mathrm{~Hz}\right)$;

${ }^{13} \mathrm{C}-\mathrm{NMR}\left(\mathrm{CDCl}_{3}\right): \delta 18.67\left(\mathrm{CH}_{3}\right), 28.82\left(\mathrm{CH}_{2}\right), 64.21\left(\mathrm{CH}_{2} \mathrm{O}\right), 65.14\left(\mathrm{CH}_{2} \mathrm{O}\right), 101.76\left(\mathrm{C}_{7}\right), 112.02$ $\left(\mathrm{C}_{5}\right), 112.10\left(\mathrm{C}_{2}\right), 113.75\left(\mathrm{C}_{4 \mathrm{a}}\right), 115.0\left(\mathrm{C}_{6 \mathrm{~b}}\right), 117.51\left(\mathrm{C}_{3 \mathrm{~b}}\right), 121.43\left(\mathrm{C}_{6 \mathrm{c}}\right), 122.40\left(\mathrm{C}_{4 \mathrm{~b}}\right), 124.26\left(\mathrm{C}_{2 \mathrm{c}}\right)$, $125.55\left(\mathrm{C}_{4}\right), 127.58\left(\mathrm{C}_{5 \mathrm{c}}\right), 127.80\left(\mathrm{C}_{5 \mathrm{~b}}\right), 130.15\left(\mathrm{C}_{4 \mathrm{c}}\right), 130.82\left(\mathrm{C}_{3 \mathrm{c}}\right), 142.91\left(\mathrm{C}_{2 \mathrm{~b}}\right), 150.74\left(\mathrm{C}_{1 \mathrm{~b}}\right), 152.50$ $\left(\mathrm{C}_{1 \mathrm{c}}\right), 155.22\left(\mathrm{C}_{7 \mathrm{a}}\right), 158.0\left(\mathrm{C}_{3}\right), 161.30\left(\mathrm{C}_{6}\right), 161.70(\mathrm{C}=\mathrm{O})$; EIMS: $m / z$ 505.0371 [M $\left.+\mathrm{H}\right]^{+}$, Calcd for $\mathrm{C}_{25} \mathrm{H}_{20} \mathrm{Cl}_{3} \mathrm{O}_{5}$ : 505.0376. Anal. Calc. for $\mathrm{C}_{25} \mathrm{H}_{19} \mathrm{Cl}_{3} \mathrm{O}_{5}$ : C 59.37, H 3.79. Found C 59.92, H 3.91.

7-\{4-[5-Chloro-2-(2,4-dichlorophenoxy)phenoxy]butoxy\}-4-methyl-2H-chromen-2-one (17). Yield 53\% (0.170, $88 \mathrm{mg})$; white solid, M.p. $111-113{ }^{\circ} \mathrm{C}$; IR $\left(\mathrm{cm}^{-1}\right): v_{\max } 2956(\mathrm{C}-\mathrm{H}), 1735(\mathrm{C}=\mathrm{O}), 1625(\mathrm{C}=\mathrm{C})$, $1474\left(\mathrm{C}=\mathrm{C}_{\mathrm{Ar}}\right), 1294(\mathrm{C}-\mathrm{O}-\mathrm{C}), 1153((\mathrm{C}=\mathrm{O})-\mathrm{O}), 851\left(\mathrm{C}-\mathrm{H}_{\mathrm{Ar}}\right), 742(\mathrm{C}-\mathrm{Cl}) ;{ }^{1} \mathrm{H}-\mathrm{NMR}\left(\mathrm{CDCl}_{3}\right): \delta 1.72-1.84$ $(2 \mathrm{H}, \mathrm{m}), 1.84-1.96(2 \mathrm{H}, \mathrm{m}), 2.44\left(\mathrm{CH}_{3}, \mathrm{~s}\right), 4.01\left(\mathrm{CH}_{2} \mathrm{O}, \mathrm{t}, J=6.0 \mathrm{~Hz}\right), 4.05\left(\mathrm{CH}_{2} \mathrm{O}, \mathrm{t}, J=5.7 \mathrm{~Hz}\right), 6.17$ $\left(\mathrm{H}_{2}, \mathrm{~s}\right), 6.69\left(\mathrm{H}_{3 \mathrm{~b}}, \mathrm{~d}, J=8.8 \mathrm{~Hz}\right), 6.80\left(\mathrm{H}_{7}, \mathrm{~d}, J=2.4 \mathrm{~Hz}\right), 6.86\left(\mathrm{H}_{5}, \mathrm{dd}, J=8.8,2.4 \mathrm{~Hz}\right), 6.97-7.0\left(\mathrm{H}_{4 \mathrm{~b}}\right.$, $\left.\mathrm{H}_{6 \mathrm{~b}}, \mathrm{~m}\right), 7.0-7.03\left(\mathrm{H}_{6 \mathrm{c}}, \mathrm{m}\right), 7.12\left(\mathrm{H}_{5 \mathrm{c}}, \mathrm{dd}, \mathrm{J}=8.9,2.5\right), 7.43\left(\mathrm{H}_{3 \mathrm{c}}, \mathrm{d}, J=2.5 \mathrm{~Hz}\right), 7.51\left(\mathrm{H}_{4}, \mathrm{~d}, J=8.6 \mathrm{~Hz}\right)$; ${ }^{13} \mathrm{C}-\mathrm{NMR}\left(\mathrm{CDCl}_{3}\right): \delta 18.67\left(\mathrm{CH}_{3}\right), 25.51\left(\mathrm{CH}_{2}\right), 25.58\left(\mathrm{CH}_{2}\right), 67.83\left(\mathrm{CH}_{2} \mathrm{O}\right), 68.62\left(\mathrm{CH}_{2} \mathrm{O}\right), 101.41\left(\mathrm{C}_{7}\right)$, $112.0\left(\mathrm{C}_{5}\right), 112.55\left(\mathrm{C}_{2}\right), 113.55\left(\mathrm{C}_{4 \mathrm{a}}\right), 114.82\left(\mathrm{C}_{6 \mathrm{~b}}\right), 118.0\left(\mathrm{C}_{3 \mathrm{~b}}\right), 121.2\left(\mathrm{C}_{6 \mathrm{c}}\right), 122.08\left(\mathrm{C}_{4 \mathrm{~b}}\right), 124.46\left(\mathrm{C}_{2 \mathrm{c}}\right)$, $125.50\left(\mathrm{C}_{4}\right), 127.61\left(\mathrm{C}_{5 \mathrm{c}}\right), 127.91\left(\mathrm{C}_{5 \mathrm{~b}}\right), 130.16\left(\mathrm{C}_{4 \mathrm{c}}\right), 130.62\left(\mathrm{C}_{3 \mathrm{c}}\right), 143.12\left(\mathrm{C}_{2 \mathrm{~b}}\right), 150.80\left(\mathrm{C}_{1 \mathrm{~b}}\right), 152.55$ $\left(\mathrm{C}_{1 \mathrm{c}}\right), 155.30\left(\mathrm{C}_{7 \mathrm{a}}\right), 155.7\left(\mathrm{C}_{3}\right), 161.35\left(\mathrm{C}_{6}\right), 162.0(\mathrm{C}=\mathrm{O})$; EIMS: $m / z 519.0536[\mathrm{M}+\mathrm{H}]^{+}$, Calcd. for $\mathrm{C}_{26} \mathrm{H}_{22} \mathrm{Cl}_{3} \mathrm{O}_{5}$ : 519.0533. Anal. Calc. for $\mathrm{C}_{26} \mathrm{H}_{21} \mathrm{Cl}_{3} \mathrm{O}_{5}$ : C 60.08, H 4.07. Found $\mathrm{C} 60.02, \mathrm{H} 4.10$.

7-(\{5-[5-Chloro-2-(2,4-dichlorophenoxy)phenoxy]pentyl\}oxy)-4-methyl-2H-chromen-2-one (18). Yield 67\% (0.206 mmol, $110 \mathrm{mg})$; white solid, M.p. 84-86 ${ }^{\circ} \mathrm{C}$; IR $\left(\mathrm{cm}^{-1}\right): v_{\max } 2936(\mathrm{C}-\mathrm{H}), 1740(\mathrm{C}=\mathrm{O})$, $1611(\mathrm{C}=\mathrm{C}), 1469\left(\mathrm{C}=\mathrm{C}_{\mathrm{Ar}}\right), 1285(\mathrm{C}-\mathrm{O}-\mathrm{C}), 1192((\mathrm{C}=\mathrm{O})-\mathrm{O}), 847\left(\mathrm{C}-\mathrm{H}_{\mathrm{Ar}}\right), 740(\mathrm{C}-\mathrm{Cl})$; ${ }^{1} \mathrm{H}-\mathrm{NMR}$ $\left(\mathrm{CDCl}_{3}\right): \delta 1.36-1.51(2 \mathrm{H}, \mathrm{m}), 1.67-1.86(4 \mathrm{H}, \mathrm{m}), 2.43\left(\mathrm{CH}_{3}, \mathrm{~s}\right), 3.98\left(\mathrm{CH}_{2} \mathrm{O}, \mathrm{t}, J=6.3 \mathrm{~Hz}\right), 3.99$ $\left(\mathrm{CH}_{2} \mathrm{O}, \mathrm{t}, J=5.9 \mathrm{~Hz}\right), 6.16\left(\mathrm{H}_{2}, \mathrm{~s}\right), 6.66\left(\mathrm{H}_{3 \mathrm{~b}}, \mathrm{~d}, J=8.8 \mathrm{~Hz}\right), 6.82\left(\mathrm{H}_{7}, \mathrm{~d}, J=2.4 \mathrm{~Hz}\right), 6.87\left(\mathrm{H}_{5}, \mathrm{dd}\right.$, $J=8.8,2.4 \mathrm{~Hz}), 6.93-7.06\left(\mathrm{H}_{4 \mathrm{~b}}, \mathrm{H}_{6 \mathrm{~b}}, \mathrm{H}_{6 \mathrm{c}}, \mathrm{m}\right), 7.10\left(\mathrm{H}_{5 \mathrm{c}}, \mathrm{dd}, J=8.8,2.5\right), 7.43\left(\mathrm{H}_{3 \mathrm{c}}, \mathrm{d}, J=2.5 \mathrm{~Hz}\right)$, $7.52\left(\mathrm{H}_{4}, \mathrm{~d}, J=8.6 \mathrm{~Hz}\right) ;{ }^{13} \mathrm{C}-\mathrm{NMR}\left(\mathrm{CDCl}_{3}\right): \delta 18.70\left(\mathrm{CH}_{3}\right), 22.45\left(\mathrm{CH}_{2}\right), 28.61\left(\mathrm{CH}_{2}\right), 28.67\left(\mathrm{CH}_{2}\right)$, $68.3\left(\mathrm{CH}_{2} \mathrm{O}\right), 68.84\left(\mathrm{CH}_{2} \mathrm{O}\right), 101.44\left(\mathrm{C}_{7}\right), 111.90\left(\mathrm{C}_{5}\right), 112.60\left(\mathrm{C}_{2}\right), 113.52\left(\mathrm{C}_{4 \mathrm{a}}\right), 114.75\left(\mathrm{C}_{6 \mathrm{~b}}\right), 117.66$ $\left(\mathrm{C}_{3 \mathrm{~b}}\right), 121.05\left(\mathrm{C}_{6 \mathrm{c}}\right), 122.36\left(\mathrm{C}_{4 \mathrm{~b}}\right), 124.27\left(\mathrm{C}_{2 \mathrm{c}}\right), 125.51\left(\mathrm{C}_{4}\right), 127.55\left(\mathrm{C}_{5 \mathrm{c}}\right), 127.66\left(\mathrm{C}_{5 \mathrm{~b}}\right), 130.08\left(\mathrm{C}_{4 \mathrm{c}}\right)$, $130.75\left(\mathrm{C}_{3 \mathrm{c}}\right), 143.0\left(\mathrm{C}_{2 \mathrm{~b}}\right), 151.0\left(\mathrm{C}_{1 \mathrm{~b}}\right), 152.61\left(\mathrm{C}_{1 \mathrm{c}}\right), 152.70\left(\mathrm{C}_{7 \mathrm{a}}\right), 155.31\left(\mathrm{C}_{3}\right), 161.40\left(\mathrm{C}_{6}\right), 162.11$ $(\mathrm{C}=\mathrm{O})$; EIMS: $m / z$ 533.0692 $[\mathrm{M}+\mathrm{H}]^{+}$, Calcd. for $\mathrm{C}_{27} \mathrm{H}_{24} \mathrm{Cl}_{3} \mathrm{O}_{5}$ : 533.0689. Anal. Calc. for $\mathrm{C}_{27} \mathrm{H}_{23} \mathrm{Cl}_{3} \mathrm{O}_{5}$ : C 60.75, H 4.34. Found $\mathrm{C} 60.60, \mathrm{H} 4.43$. 
7-(\{8-[5-Chloro-2-(2,4-dichlorophenoxy)phenoxy]octyl\}oxy)-4-methyl-2H-chromen-2-one (19). Yield 75\% (0.204 mmol, $117 \mathrm{mg})$; yellow pale oil; IR $\left(\mathrm{cm}^{-1}\right): v_{\max } 2936(\mathrm{C}-\mathrm{H}), 1729(\mathrm{C}=\mathrm{O}), 1613(\mathrm{C}=\mathrm{C})$, $1474\left(\mathrm{C}=\mathrm{C}_{\mathrm{Ar}}\right), 1268(\mathrm{C}-\mathrm{O}-\mathrm{C}), 1146((\mathrm{C}=\mathrm{O})-\mathrm{O}), 839\left(\mathrm{C}-\mathrm{H}_{\mathrm{Ar}}\right), 742(\mathrm{C}-\mathrm{Cl}) ;{ }^{1} \mathrm{H}-\mathrm{NMR}\left(\mathrm{CDCl}_{3}\right): \delta 1.16-1.37$ $(6 \mathrm{H}, \mathrm{m}), 1.39-1.55(2 \mathrm{H}, \mathrm{m}), 1.59-1.72(2 \mathrm{H}, \mathrm{m}), 1.77-1.94(2 \mathrm{H}, \mathrm{m}), 2.43\left(\mathrm{CH}_{3}, \mathrm{~s}\right), 3.94\left(\mathrm{CH}_{2} \mathrm{O}, \mathrm{t}\right.$, $J=6.2 \mathrm{~Hz}), 4.05\left(\mathrm{CH}_{2} \mathrm{O}, \mathrm{t}, J=6.5 \mathrm{~Hz}\right), 6.16\left(\mathrm{H}_{2}, \mathrm{~s}\right), 6.66\left(\mathrm{H}_{3 \mathrm{~b}}, \mathrm{~d}, J=8.8 \mathrm{~Hz}\right), 6.84\left(\mathrm{H}_{7}, \mathrm{~d}, J=2.5 \mathrm{~Hz}\right)$, $6.89\left(\mathrm{H}_{5}, \mathrm{dd}, J=8.8,2.5 \mathrm{~Hz}\right), 6.95\left(\mathrm{H}_{4 \mathrm{~b}}, \mathrm{dd}, J=8.8,2.5 \mathrm{~Hz}\right), 6.97-7.06\left(\mathrm{H}_{6 \mathrm{~b}}, \mathrm{H}_{6 \mathrm{c}}, \mathrm{m}\right), 7.11\left(\mathrm{H}_{5 \mathrm{c}}, \mathrm{dd}\right.$, $J=8.8,2.5), 7.44\left(\mathrm{H}_{3 \mathrm{c}}, \mathrm{d}, J=2.5 \mathrm{~Hz}\right), 7.52\left(\mathrm{H}_{4}, \mathrm{~d}, J=8.8 \mathrm{~Hz}\right) ;{ }^{13} \mathrm{C}-\mathrm{NMR}\left(\mathrm{CDCl}_{3}\right): \delta 18.71\left(\mathrm{CH}_{3}\right)$, $25.70\left(\mathrm{CH}_{2}\right), 25.90\left(\mathrm{CH}_{2}\right), 28.91\left(\mathrm{CH}_{2}\right), 29.0\left(\mathrm{CH}_{2}\right), 29.14\left(\mathrm{CH}_{2}\right), 29.24\left(\mathrm{CH}_{2}\right), 68.57\left(\mathrm{CH}_{2} \mathrm{O}\right), 68.96$ $\left(\mathrm{CH}_{2} \mathrm{O}\right), 101.36\left(\mathrm{C}_{7}\right), 111.82\left(\mathrm{C}_{5}\right), 112.71\left(\mathrm{C}_{2}\right), 113.43\left(\mathrm{C}_{4 \mathrm{a}}\right), 114.62\left(\mathrm{C}_{6 \mathrm{~b}}\right), 117.62\left(\mathrm{C}_{3 \mathrm{~b}}\right), 120.85\left(\mathrm{C}_{6 \mathrm{c}}\right)$, $122.36\left(\mathrm{C}_{4 \mathrm{~b}}\right), 124.21\left(\mathrm{C}_{2 \mathrm{c}}\right), 125.51\left(\mathrm{C}_{4}\right), 127.51\left(\mathrm{C}_{5 \mathrm{c}}\right), 127.60\left(\mathrm{C}_{5 \mathrm{~b}}\right), 130.06\left(\mathrm{C}_{4 \mathrm{c}}\right), 130.73\left(\mathrm{C}_{3 \mathrm{c}}\right), 142.82$ $\left(\mathrm{C}_{2 \mathrm{~b}}\right), 151.1\left(\mathrm{C}_{1 \mathrm{~b}}\right), 152.66\left(\mathrm{C}_{1 \mathrm{c}}\right), 152.71\left(\mathrm{C}_{7 \mathrm{a}}\right), 155.32\left(\mathrm{C}_{3}\right), 161.44\left(\mathrm{C}_{6}\right), 162.25(\mathrm{C}=\mathrm{O})$; EIMS: $\mathrm{m} / \mathrm{z}$ $575.1156[\mathrm{M}+\mathrm{H}]^{+}$, Calcd. for $\mathrm{C}_{30} \mathrm{H}_{30} \mathrm{Cl}_{3} \mathrm{O}_{5}: 575.1159$.

7-\{3-[5-Chloro-2-(2,4-dichlorophenoxy)phenoxy]propoxy\}-4H-chromen-4-one (25). Yield 79\% (0.279 mmol, $137 \mathrm{mg})$; yellow pale oil; IR $\left(^{-1}\right): v_{\max } 2941(\mathrm{C}-\mathrm{H}), 1651(\mathrm{C}=\mathrm{O}), 1599(\mathrm{C}=\mathrm{C}), 1496$ $\left(\mathrm{C}=\mathrm{C}_{\mathrm{Ar}}\right), 1267(\mathrm{C}-\mathrm{O}-\mathrm{C}), 1190((\mathrm{C}=\mathrm{O})-\mathrm{O}), 812\left(\mathrm{C}-\mathrm{H}_{\mathrm{Ar}}\right), 740(\mathrm{C}-\mathrm{Cl}) ;{ }^{1} \mathrm{H}-\mathrm{NMR}\left(\mathrm{CDCl}_{3}\right): \delta 2.15-2.25$ $(2 \mathrm{H}, \mathrm{m}), 3.97\left(\mathrm{CH}_{2} \mathrm{O}, \mathrm{t}, J=6.0 \mathrm{~Hz}\right), 4.18\left(\mathrm{CH}_{2} \mathrm{O}, \mathrm{t}, J=5.8 \mathrm{~Hz}\right), 6.31\left(\mathrm{H}_{2}, \mathrm{~d}, J=6.0 \mathrm{~Hz}\right), 6.60\left(\mathrm{H}_{3 \mathrm{~b}}, \mathrm{~d}\right.$, $J=8.8 \mathrm{~Hz}), 6.73\left(\mathrm{H}_{4}, \mathrm{~d}, J=2.3 \mathrm{~Hz}\right), 6.91\left(\mathrm{H}_{6}, \mathrm{dd}, J=9.1,2.3 \mathrm{~Hz}\right), 6.95\left(\mathrm{H}_{4 \mathrm{~b}}, \mathrm{dd}, J=8.7,2.6 \mathrm{~Hz}\right)$, 6.98-7.02 $\left(\mathrm{H}_{6 \mathrm{~b}}, \mathrm{H}_{6 \mathrm{c}}, \mathrm{m}\right), 7.02-7.06\left(\mathrm{H}_{5 \mathrm{c}}, \mathrm{m}\right), 7.42\left(\mathrm{H}_{3 \mathrm{c}}, \mathrm{d}, J=2.5 \mathrm{~Hz}\right), 7.82\left(\mathrm{H}_{3}, \mathrm{~d}, J=6.0 \mathrm{~Hz}\right), 8.12$ $\left(\mathrm{H}_{7}, \mathrm{~d}, J=9.0 \mathrm{~Hz}\right) ;{ }^{13} \mathrm{C}-\mathrm{NMR}\left(\mathrm{CDCl}_{3}\right): \delta 28.77\left(\mathrm{CH}_{2}\right), 64.27\left(\mathrm{CH}_{2} \mathrm{O}\right), 67.58\left(\mathrm{CH}_{2} \mathrm{O}\right), 100.86\left(\mathrm{C}_{4}\right)$, $112.97\left(\mathrm{C}_{6}\right), 114.70\left(\mathrm{C}_{2}\right), 114.83\left(\mathrm{C}_{6 \mathrm{~b}}\right), 117.38\left(\mathrm{C}_{3 \mathrm{~b}}\right), 118.87\left(\mathrm{C}_{7 \mathrm{a}}\right), 121.45\left(\mathrm{C}_{6 \mathrm{c}}\right), 122.52\left(\mathrm{C}_{4 \mathrm{~b}}\right), 124.0$ $\left(\mathrm{C}_{2 \mathrm{c}}\right), 127.21\left(\mathrm{C}_{7}\right), 127.59\left(\mathrm{C}_{5 \mathrm{c}}\right), 127.75\left(\mathrm{C}_{5 \mathrm{~b}}\right), 130.12\left(\mathrm{C}_{4 \mathrm{c}}\right), 130.9\left(\mathrm{C}_{3 \mathrm{c}}\right), 142.75\left(\mathrm{C}_{2 \mathrm{~b}}\right), 150.72\left(\mathrm{C}_{1 \mathrm{~b}}\right)$, $152.53\left(\mathrm{C}_{1 \mathrm{c}}\right), 154.91\left(\mathrm{C}_{3}\right), 158.20\left(\mathrm{C}_{4 \mathrm{a}}\right), 163.13\left(\mathrm{C}_{5}\right), 177.07(\mathrm{C}=\mathrm{O})$; EIMS: $m / z 513.0032[\mathrm{M}+\mathrm{Na}]^{+}$, Calcd. for $\mathrm{C}_{24} \mathrm{H}_{17} \mathrm{Cl}_{3} \mathrm{O}_{5} \mathrm{Na}$ : 513.0039.

7-\{4-[5-Chloro-2-(2,4-dichlorophenoxy)phenoxy]butoxy\}-4H-chromen-4-one (26). Yield 72\% (0.243 mmol, $122 \mathrm{mg})$; yellow solid, M.p. $75-79{ }^{\circ} \mathrm{C}$; IR $\left(\mathrm{cm}^{-1}\right): v_{\max } 2934(\mathrm{C}-\mathrm{H}), 1662(\mathrm{C}=\mathrm{O}), 1598(\mathrm{C}=\mathrm{C})$, $1471\left(\mathrm{C}=\mathrm{C}_{\mathrm{Ar}}\right), 1259(\mathrm{C}-\mathrm{O}-\mathrm{C}), 1190((\mathrm{C}=\mathrm{O})-\mathrm{O}), 812\left(\mathrm{C}-\mathrm{H}_{\mathrm{Ar}}\right), 740(\mathrm{C}-\mathrm{Cl}) ;{ }^{1} \mathrm{H}-\mathrm{NMR}\left(\mathrm{CDCl}_{3}\right): \delta 1.73-1.85$ $(2 \mathrm{H}, \mathrm{m}), 1.85-1.97(2 \mathrm{H}, \mathrm{m}), 4.03\left(\mathrm{CH}_{2} \mathrm{O}, \mathrm{t}, J=6.1 \mathrm{~Hz}\right), 4.05\left(\mathrm{CH}_{2} \mathrm{O}, \mathrm{t}, J=5.7 \mathrm{~Hz}\right), 6.32\left(\mathrm{H}_{2}, \mathrm{~d}\right.$, $J=6.1 \mathrm{~Hz}), 6.68\left(\mathrm{H}_{3 \mathrm{~b}}, \mathrm{~d}, J=8.8 \mathrm{~Hz}\right), 6.82\left(\mathrm{H}_{4}, \mathrm{~d}, J=2.3 \mathrm{~Hz}\right), 6.92-7.0\left(\mathrm{H}_{6}, \mathrm{H}_{6 \mathrm{~b}}, \mathrm{~m}\right), 7.02-7.03\left(\mathrm{H}_{6 \mathrm{c}}\right.$, $\mathrm{m}), 7.12\left(\mathrm{H}_{5 \mathrm{c}}, \mathrm{dd}, J=8.8,2.5 \mathrm{~Hz}\right), 7.43\left(\mathrm{H}_{3 \mathrm{c}}, \mathrm{d}, J=2.5 \mathrm{~Hz}\right), 7.81\left(\mathrm{H}_{3}, \mathrm{~d}, J=6.1 \mathrm{~Hz}\right), 8.13\left(\mathrm{H}_{7}, \mathrm{~d}\right.$, $J=8.9 \mathrm{~Hz}) ;{ }^{13} \mathrm{C}-\mathrm{NMR}\left(\mathrm{CDCl}_{3}\right): \delta 25.53\left(2 \mathrm{CH}_{2}\right), 67.93\left(\mathrm{CH}_{2} \mathrm{O}\right), 68.58\left(\mathrm{CH}_{2} \mathrm{O}\right), 100.84\left(\mathrm{C}_{4}\right), 112.96$ $\left(\mathrm{C}_{6}\right), 114.76\left(\mathrm{C}_{2}\right), 114.83\left(\mathrm{C}_{6 \mathrm{~b}}\right), 117.91\left(\mathrm{C}_{3 \mathrm{~b}}\right), 118.72\left(\mathrm{C}_{7 \mathrm{a}}\right), 121.19\left(\mathrm{C}_{6 \mathrm{c}}\right), 122.11\left(\mathrm{C}_{4 \mathrm{~b}}\right), 124.41\left(\mathrm{C}_{2 \mathrm{c}}\right)$, $127.19\left(\mathrm{C}_{7}\right), 127.62\left(\mathrm{C}_{5 \mathrm{c}}\right), 127.89\left(\mathrm{C}_{5 \mathrm{~b}}\right), 130.16\left(\mathrm{C}_{4 \mathrm{c}}\right), 130.65\left(\mathrm{C}_{3 \mathrm{c}}\right), 143.04\left(\mathrm{C}_{2 \mathrm{~b}}\right), 150.76\left(\mathrm{C}_{1 \mathrm{~b}}\right), 152.51$ $\left(\mathrm{C}_{1 \mathrm{c}}\right), 154.86\left(\mathrm{C}_{3}\right), 158.24\left(\mathrm{C}_{4 \mathrm{a}}\right), 163.41\left(\mathrm{C}_{5}\right), 177.07(\mathrm{C}=\mathrm{O})$; EIMS: $m / z$ 505.0376 [M + H] $]^{+}$, Calcd. for $\mathrm{C}_{25} \mathrm{H}_{20} \mathrm{Cl}_{3} \mathrm{O}_{5}$ : 505.0376. Anal. Calc. for $\mathrm{C}_{25} \mathrm{H}_{19} \mathrm{Cl}_{3} \mathrm{O}_{5}$ : C 59.37, H 3.79. Found C 59.58, H 3.79.

7-(\{5-[5-Chloro-2-(2,4-dichlorophenoxy)phenoxy]pentyl\}oxy)-4H-chromen-4-one (27). Yield 58\% (0.186 mmol, $96 \mathrm{mg})$; yellow solid, M.p. $74-7{ }^{\circ} \mathrm{C}$; IR $\left(\mathrm{cm}^{-1}\right): v_{\max } 2951(\mathrm{C}-\mathrm{H}), 1649(\mathrm{C}=\mathrm{O}), 1596$ $(\mathrm{C}=\mathrm{C}), 1475\left(\mathrm{C}=\mathrm{C}_{\mathrm{Ar}}\right), 1268(\mathrm{C}-\mathrm{O}-\mathrm{C}), 1195((\mathrm{C}=\mathrm{O})-\mathrm{O}), 809\left(\mathrm{C}-\mathrm{H}_{\mathrm{Ar}}\right), 740(\mathrm{C}-\mathrm{Cl}) ;{ }^{1} \mathrm{H}-\mathrm{NMR}\left(\mathrm{CDCl}_{3}\right): \delta$ $1.35-1.51(2 \mathrm{H}, \mathrm{m}), 1.67-1.86(4 \mathrm{H}, \mathrm{m}), 3.98\left(2 \mathrm{CH}_{2} \mathrm{O}, \mathrm{t}, J=6.1 \mathrm{~Hz}\right), 6.30\left(\mathrm{H}_{2}, \mathrm{~d}, J=6.3 \mathrm{~Hz}\right), 6.65\left(\mathrm{H}_{3 \mathrm{~b}}\right.$, $\mathrm{d}, J=8.9 \mathrm{~Hz}), 6.84\left(\mathrm{H}_{4}, \mathrm{~d}, J=2.0 \mathrm{~Hz}\right), 6.92-7.04\left(\mathrm{H}_{5 \mathrm{c}}, \mathrm{H}_{6}, \mathrm{H}_{6 \mathrm{~b}}, \mathrm{H}_{6 \mathrm{c}}, \mathrm{m}\right), 7.09\left(\mathrm{H}_{4 \mathrm{~b}}, \mathrm{dd}, J=8.7\right.$, 
$2.6 \mathrm{~Hz}), 7.42\left(\mathrm{H}_{3 \mathrm{c}}, \mathrm{d}, J=2.4 \mathrm{~Hz}\right), 7.80\left(\mathrm{H}_{3}, \mathrm{~d}, J=6.1 \mathrm{~Hz}\right), 8.13\left(\mathrm{H}_{7}, \mathrm{~d}, J=9.0 \mathrm{~Hz}\right) ;{ }^{13} \mathrm{C}-\mathrm{NMR}\left(\mathrm{CDCl}_{3}\right)$ :

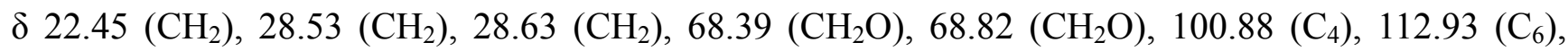
$114.74\left(\mathrm{C}_{2}\right), 114.83\left(\mathrm{C}_{6 \mathrm{~b}}\right), 117.60\left(\mathrm{C}_{3 \mathrm{~b}}\right), 118.70\left(\mathrm{C}_{7 \mathrm{a}}\right), 121.10\left(\mathrm{C}_{6 \mathrm{c}}\right), 122.41\left(\mathrm{C}_{4 \mathrm{~b}}\right), 124.22\left(\mathrm{C}_{2 \mathrm{c}}\right), 127.15$ $\left(\mathrm{C}_{7}\right), 127.55\left(\mathrm{C}_{5 \mathrm{c}}\right), 127.61\left(\mathrm{C}_{5 \mathrm{~b}}\right), 130.10\left(\mathrm{C}_{4 \mathrm{c}}\right), 130.80\left(\mathrm{C}_{3 \mathrm{c}}\right), 142.83\left(\mathrm{C}_{2 \mathrm{~b}}\right), 151.0\left(\mathrm{C}_{1 \mathrm{~b}}\right), 152.71\left(\mathrm{C}_{1 \mathrm{c}}\right)$, $154.86\left(\mathrm{C}_{3}\right), 158.27\left(\mathrm{C}_{4 \mathrm{a}}\right), 163.54\left(\mathrm{C}_{5}\right), 177.04(\mathrm{C}=\mathrm{O})$; EIMS: $m / z 519.0538[\mathrm{M}+\mathrm{H}]^{+}$, Calcd. for $\mathrm{C}_{26} \mathrm{H}_{22} \mathrm{Cl}_{3} \mathrm{O}_{5}$ : 519.0533. Anal. Calcd. for $\mathrm{C}_{26} \mathrm{H}_{21} \mathrm{Cl}_{3} \mathrm{O}_{5}$ : C 60.08, H 4.07. Found $\mathrm{C}$ 59.39, H 4.08.

7-(\{8-[5-Chloro-2-(2,4-dichlorophenoxy)phenoxy]octyl\}oxy)-4H-chromen-4-one (28). Yield 50\% (0.142 mmol, $79 \mathrm{mg})$; yellow pale oil; IR $\left(\mathrm{cm}^{-1}\right): v_{\max } 2932(\mathrm{C}-\mathrm{H}), 1649(\mathrm{C}=\mathrm{O}), 1599(\mathrm{C}=\mathrm{C}), 1496$ $\left(\mathrm{C}=\mathrm{C}_{\mathrm{Ar}}\right), 1268(\mathrm{C}-\mathrm{O}-\mathrm{C}), 1191((\mathrm{C}=\mathrm{O})-\mathrm{O}), 810\left(\mathrm{C}-\mathrm{H}_{\mathrm{Ar}}\right), 740(\mathrm{C}-\mathrm{Cl}) ;{ }^{1} \mathrm{H}-\mathrm{NMR}\left(\mathrm{CDCl}_{3}\right): \delta$ 1.17-1.39 $(4 \mathrm{H}, \mathrm{m}), 1.40-1.58(4 \mathrm{H}, \mathrm{m}), 1.60-1.75(2 \mathrm{H}, \mathrm{m}), 1.79-1.94(2 \mathrm{H}, \mathrm{m}), 3.95\left(\mathrm{CH}_{2} \mathrm{O}, \mathrm{t}, J=6.1 \mathrm{~Hz}\right), 4.08$ $\left(\mathrm{CH}_{2} \mathrm{O}, \mathrm{t}, J=6.4 \mathrm{~Hz}\right), 6.32\left(\mathrm{H}_{2}, \mathrm{~d}, J=6.1 \mathrm{~Hz}\right), 6.66\left(\mathrm{H}_{3 \mathrm{~b}}, \mathrm{~d}, J=8.7 \mathrm{~Hz}\right), 6.87\left(\mathrm{H}_{4}, \mathrm{~d}, J=2.0 \mathrm{~Hz}\right)$, 6.93-7.06 ( $\left.\mathrm{H}_{5 \mathrm{c}}, \mathrm{H}_{6}, \mathrm{H}_{6 \mathrm{~b}}, \mathrm{H}_{6 \mathrm{c}}, \mathrm{m}\right), 7.11\left(\mathrm{H}_{4 \mathrm{~b}}, \mathrm{dd}, J=8.9,2.4 \mathrm{~Hz}\right), 7.45\left(\mathrm{H}_{3 \mathrm{c}}, \mathrm{d}, J=2.4 \mathrm{~Hz}\right), 7.81\left(\mathrm{H}_{3}, \mathrm{~d}\right.$, $J=6.1 \mathrm{~Hz}), 8.15\left(\mathrm{H}_{7}, \mathrm{~d}, J=8.9 \mathrm{~Hz}\right) \cdot{ }^{13} \mathrm{C}-\mathrm{NMR}\left(\mathrm{CDCl}_{3}\right)$ : $\delta 25.69\left(\mathrm{CH}_{2}\right), 25.88\left(\mathrm{CH}_{2}\right), 28.92\left(\mathrm{CH}_{2}\right)$, $28.97\left(\mathrm{CH}_{2}\right), 29.13\left(\mathrm{CH}_{2}\right), 29.20\left(\mathrm{CH}_{2}\right), 68.67\left(\mathrm{CH}_{2} \mathrm{O}\right), 69.0\left(\mathrm{CH}_{2} \mathrm{O}\right), 100.89\left(\mathrm{C}_{4}\right), 112.95\left(\mathrm{C}_{6}\right), 114.68$ $\left(\mathrm{C}_{2}\right), 114.87\left(\mathrm{C}_{6 \mathrm{~b}}\right), 117.64\left(\mathrm{C}_{3 \mathrm{~b}}\right), 118.66\left(\mathrm{C}_{7 \mathrm{a}}\right), 120.88\left(\mathrm{C}_{6 \mathrm{c}}\right), 122.35\left(\mathrm{C}_{4 \mathrm{~b}}\right), 124.25\left(\mathrm{C}_{2 \mathrm{c}}\right), 127.18\left(\mathrm{C}_{7}\right), 127.50$ $\left(\mathrm{C}_{5 \mathrm{c}}\right), 127.62\left(\mathrm{C}_{5 \mathrm{~b}}\right), 130.73\left(\mathrm{C}_{4 \mathrm{c}}\right), 130.80\left(\mathrm{C}_{3 \mathrm{c}}\right), 142.88\left(\mathrm{C}_{2 \mathrm{~b}}\right), 151.09\left(\mathrm{C}_{1 \mathrm{~b}}\right), 152.72\left(\mathrm{C}_{1 \mathrm{c}}\right), 154.82\left(\mathrm{C}_{3}\right)$, 158.29 $\left(\mathrm{C}_{4 \mathrm{a}}\right), 163.71\left(\mathrm{C}_{5}\right), 177.1(\mathrm{C}=\mathrm{O})$; EIMS: $m / z 561.1003[\mathrm{M}+\mathrm{H}]^{+}$, Calcd. for $\mathrm{C}_{29} \mathrm{H}_{28} \mathrm{Cl}_{3} \mathrm{O}_{5}: 561.1002$.

Solubility: Compounds 7-10, 16-19 and 25-28 are soluble in dichloromethane, ether and ethyl acetate, which is in agreement with their low polarity.

\subsection{Biological Activity Assays}

The compounds were subjected to in vitro cytotoxic activity on mammalian cells and leishmanicidal activity on intracellular amastigotes of $L$. panamensis.

\subsubsection{In Vitro Cytotoxic Activity in Mammalian Cells}

The cytotoxic activity of the compounds was assessed based on the viability of the human promonocytic cell line U937 (ATCC CRL-1593.2 ${ }^{\mathrm{TM}}$ ) evaluated by the MTT (3-(4,5-dimethylthiazol-2yl)-2,5-diphenyltetrazolium bromide) assay [41]. In brief, cells were grown in 96-well cell-culture dishes at a concentration of 100,000 cells $/ \mathrm{mL}$ in RPMI-1640 supplemented with $10 \%$ FBS and the corresponding concentrations of the compounds, starting at $200 \mu \mathrm{g} / \mathrm{mL}$ in duplicate. The cells were incubated at $37{ }^{\circ} \mathrm{C}$ with $5 \% \mathrm{CO}_{2}$ for $72 \mathrm{~h}$ in the presence of the compounds, and then the effect was determined using the MTT assay, incubating at $37{ }^{\circ} \mathrm{C}$ for $3 \mathrm{~h}$. The effect of the compounds was determined by measuring the activity of the mitochondrial dehydrogenase by adding $10 \mu \mathrm{L} / \mathrm{well}$ of MTT solution $(0.5 \mathrm{mg} / \mathrm{mL})$ and incubating at $37{ }^{\circ} \mathrm{C}$ for $3 \mathrm{~h}$. The reaction was stopped by adding a $50 \%$ isopropanol solution with $10 \%$ sodium dodecyl sulfate for $30 \mathrm{~min}$. Cell viability was determined based on the quantity of formazan produced, according to the optical density (O.D) obtained at $570 \mathrm{~nm}$ in a Bio-Rad (Hercules, CA, USA) ELISA instrument. Cultured cells in the absence of extracts were used as viability controls, while meglumine antimoniate and amphotericin B were used as cytotoxicity controls. Assays were performed twice with three replicates per each concentration tested. 


\subsubsection{Activity against Intracellular Amastigotes}

The leishmanicidal activity of compounds was evaluated on intracellular amastigotes of L. panamensis transfected with the green fluorescent protein gene (MHOM/CO/87/UA140pIR-GFP) [42]. Effect of each compound was determined according to the inhibition of the infection evidenced by both decrease of the infected cells and decrease of intracellular parasite load. Briefly, U-937 human cells at a concentration of $3 \times 10^{5}$ cells $/ \mathrm{mL}$ in RPMI 1640 and $0.1 \mu \mathrm{g} / \mathrm{mL}$ of PMA (phorbol-12-myristate-13-acetate) were infected with promastigotes in stationary phase growth in a 15:1 parasites per cell ratio and incubated at $34{ }^{\circ} \mathrm{C}$ and $5 \% \mathrm{CO}_{2}$ for $3 \mathrm{~h}$. Cells were washed two times with phosphate buffer solution (PBS) to eliminate not internalized parasites. Fresh RPMI $16401 \mathrm{~mL}$ was added and cells were incubated during $24 \mathrm{~h}$ to guarantee multiplication of intracellular parasites.

After $24 \mathrm{~h}$ of infection, the culture medium was replaced by fresh culture medium containing each compound at concentrations of $20 \mu \mathrm{g} / \mathrm{mL}$. After $72 \mathrm{~h}$, the inhibition of the infection progress was determined. Cells were removed from the bottom plate with a trypsin/EDTA $(250 \mathrm{mg})$ solution. Recovered cells were centrifuged at $1100 \mathrm{rpm}$ during $10 \mathrm{~min}$ at $4{ }^{\circ} \mathrm{C}$, the supernatant was discarded and cells were washed with $1 \mathrm{~mL}$ of cold PBS and centrifuged at $1100 \mathrm{rpm}$ during $10 \mathrm{~min}$ at $4{ }^{\circ} \mathrm{C}$. Supernatant was discarded and cells were suspended in $500 \mu \mathrm{L}$ of PBS and analyzed by flow cytometry (FC 500MPL, Cytomics, Brea, CA, USA) counting 20.000 events. All determinations for each compound and standards were carried out in triplicate, in two isolated experiments $[41,42]$. Activity of tested compounds was carried out in parallel with infection progress in culture medium alone and in culture medium with amphotericin B $0.05 \mu \mathrm{g} / \mathrm{mL}$ and meglumine antimoniate $(10.0 \mu \mathrm{g} / \mathrm{mL})$ as control drugs. Compounds that showed growing inhibition percentages higher than $50 \%$ were then evaluated at four additional concentrations to determine the $50 \%$ effective concentration $\left(\mathrm{EC}_{50}\right)$. The infected cells were exposed against each concentration of synthesized compounds during $72 \mathrm{~h}$, then, cells were removed and tested by flow cytometry as described before.

\subsubsection{Statistical Analysis}

Cytotoxicity was determined according to viability and mortality percentages obtained for each isolated experiment (compounds, amphotericin B, meglumine antimoniate and culture medium alone). The results were expressed as 50 lethal concentrations $\left(\mathrm{LC}_{50}\right)$, that corresponds to the concentration necessary to eliminate $50 \%$ of cells, calculated by Probit analysis [45]. Percentage of viability was calculated by Equation (1), where the optical density (O.D) of control, corresponds to $100 \%$ of viability. In turn, mortality percentage corresponds to $100 \%$ viability:

$$
\% \text { Viability }=(\text { O.D Exposed cells }) /(\text { O.D Control cells }) \times 100
$$

The degree of toxicity was established according to the $\mathrm{LC}_{50}$ value using the following scale: highly toxic: $\mathrm{LC}_{50}<50 \mu \mathrm{g} / \mathrm{mL}$, toxic: $\mathrm{LC}_{50}>50$ to $<100 \mu \mathrm{g} / \mathrm{mL}$; moderately toxic: $\mathrm{LC}_{50}>100$ to $<200 \mu \mathrm{g} / \mathrm{mL}$ and potentially non-toxic: $\mathrm{LC}_{50}>200 \mu \mathrm{g} / \mathrm{mL}$.

Antileishmanial activity was determined according to percentage of infected cells and parasite load obtained for each experimental condition by the cytometer. Percentage of infected cells was determined as the number of positive events by double fluorescence (green for parasites and red for 
cells) using dotplot analysis. On the other hand, the parasitic load was determined by analysis of mean fluorescence intensity (MFI) [41].

The parasitemia inhibition was calculated by Equation (2), where the MFI of control, corresponds to $100 \%$ of parasitemia. In turn, inhibition percentage corresponds to $100 \%$ Parasitemia. Results of antileishmanial activity was expressed as $50 \%$ effective concentrations $\left(\mathrm{EC}_{50}\right)$ determined by the Probit method [45]:

$$
\% \text { Parasitemia }=(\text { MFI Exposed parasites }) /(\text { MFI Control parasites }) \times 100
$$

The degree of leishmanicidal activity was established according to the $\mathrm{EC}_{50}$ value, using the following scale: Highly active: $\mathrm{EC}_{50}<20 \mu \mathrm{g} / \mathrm{mL}$, moderately active: $\mathrm{EC}_{50}>20$ to $<100 \mu \mathrm{g} / \mathrm{mL}$; potentially non active: $\mathrm{EC}_{50}>100 \mu \mathrm{g} / \mathrm{mL}$.

The selectivity index (SI), was calculated by dividing the cytotoxic activity and the leishmanicidal activity using the following formula: $\mathrm{SI}=\mathrm{CL}_{50} / \mathrm{CE}_{50}$. Cytotoxic compound: $\mathrm{LC}_{50}<100 \mu \mathrm{g} / \mathrm{mL}$. Non-cytotoxic compound: $\mathrm{LC}_{50}>200 \mu \mathrm{g} / \mathrm{mL}$.

\section{Conclusions}

The design, synthesis, and antileishmanial screening of twelve triclosan derivatives are reported. Several of the synthetic compounds have potential as templates for drugs development. Owing to the high leishmanicidal activity and the low cytotoxicity we consider that compounds 7-9 and $\mathbf{1 7}$ are good candidates. Studies on an animal model of leishmaniasis are needed to confirm the results observed in vitro. On the other hand, compounds 25-27 that were active against Leishmania parasite but toxic for mammalian cells still have potential to be considered as candidates for antileishmanial drug development. However, more studies on toxicity using other cell lines are needed to discriminate whether the toxicity shown by these compounds is against tumor or non-tumor cells. The results indicate that compounds containing small alkyl chains show better selectivity indices. Moreover, Michael acceptor moieties may modify both the leishmanicidal activity and cytotoxicity. The mechanism of action of these promising compounds also needs to be addressed.

\section{Acknowledgments}

The authors thank COLCIENCIAS (contract No. 0333-2013, code: 111556933423) and the Universidad de Antioquia (Estrategia de Sostenibilidad 2013-2014 and CIDEPRO) for financial support.

\section{Author Contributions}

Conceived, designed the synthesis and spectroscopy analysis: WC, MC and FO. Performed the chemical experiments: EO, SV and CR. Designed, performed and analysis the biological experiments: SMR and IDV. Wrote the paper: WC and SMR.

\section{Conflicts of Interest}

The authors declare no conflict of interest. 


\section{References}

1. Alvar, J.; Vélez, I.D.; Bern, C.; Herrero, M.; Desjeux, P.; Cano, J.; Jannin, J.; Den Boer, M.; WHO Leishmaniasis Control Team. Leishmaniasis worldwide and global estimates of its incidence. PLoS One 2012, 7, e35671.

2. World Health Organization. Control of Leishmaniasis: Report of a Meeting of the WHO Expert Committee on the Control of Leishmaniases. Presented at WHO Technical Report Series, No. 949, Geneva, Switzerland, 22-26 March 2010.

3. Fontenele e Silva, J.S.; Galvao, T.F.; Pereira, M.G.; Silva, M.T. Treatment of american tegumentary leishmaniasis in special populations: A summary of evidence. Rev. Soc. Bras. Med. Trop. 2013, 46, 669-677.

4. Tanne, J.H. How collaboration is providing new drugs for neglected diseases. BMJ 2012, 344, e2453.

5. Kapoor, M.; Reddy, C.; Krishnasastry, M.V.; Surolia, N.; Surolia, A. Slow-tight-binding inhibition of enoyl-acyl carrier protein reductase from Plasmodium falciparum by triclosan. Biochem. J. 2004, 381, 719-724.

6. Perozzo, R.; Kuo, M.; Sidhu, A.; Valiyaveettil, J.T.; Bittman, R.; Jacobs, W.R., Jr.; Fidock, D.A.; Sacchettini, J.C.; Structural elucidation of the specificity of the antibacterial agent triclosan for malarial enoyl acyl carrier protein reductase. J. Biol. Chem. 2002, 277, 13106-13114.

7. Surolia, N.; Surolia, A. Triclosan offers protection against blood stages of malaria by inhibiting enoyl-ACP reductase of Plasmodium falciparum. Nat. Med. 2001, 7, 167-173.

8. McLeod, R.; Muench, S.P.; Rafferty, J.B.; Kyle, D.E.; Mui, E.J.; Kirisits, M.J.; Mack, D.G.; Roberts, C.W.; Samuel, B.U.; Lyons, R.E.; et al. Triclosan inhibits the growth of Plasmodium falciparum and Toxoplasma gondii by inhibition of apicomplexan Fab I. Int. J. Parasitol. 2001, 31, 109-113.

9. Arango, V.; Domínguez, J.J.; Cardona, W.; Robledo, S.M.; Muñoz, D.L.; Figadere, B.; Saéz, J. Synthesis and leishmanicidal activity of quinoline-triclosan and quinoline-eugenol hybrids. Med. Chem. Res. 2012, 21, 3445-3454.

10. Kayser, O.; Kiderlen, A.F. In vitro leishmanicidal activity of naturally occurring chalcones. Phytother. Res. 2001, 15, 148-152.

11. Liu, M.; Wilairat, P.; Croft, S.L.; Tand, A.L.; Go, M.L. Structure-activity relationships of antileishmanial and antimalarial chalcones. Bioorg. Med. Chem. 2003, 11, 2729-2738.

12. Boeck, P.; Bandeira Falcão, C.A.; Leal, P.C.; Yones, R.A.; Filho, V.C.; Torres-Santos, E.C.; Rossi-Bergmann, B. Synthesis of chalcone analogues with increased antileishmanial activity. Bioorg. Med. Chem. 2006, 14, 1538-1545.

13. Chen, M.; Zhai, L.; Christensen, S.B.; Theander, T.G.; Kharazmi, A. Inhibition of Fumarate Reductase in Leishmania major and L. donovani by Chalcones. Antimicrobiol. Agents Chemother. 2001, 45, 2023-2029.

14. Morabito, G.; Trombetta, D.; Singh Brajendra, K.; Prasad Ashok, K.; Parmar Virinder, S.; Naccari, C.; Saija, A.; Cristani, M.; Firuzi, O.; Saso, L. Antioxidant properties of 4-methylcoumarins in in vitro cell-free systems. Biochimie 2010, 92, 1107-1117. 
15. Grimm, E.L.; Brideau, C.; Chauret, N.; Chan, C.C.; Delorme, D.; Ducharme, Y.; Ethier, D.; Falgueyret, J.P.; Friesen, R.W; Guay, J.; et al. Substituted coumarins as potent 5-lipoxygenase inhibitors. Bioorg. Med. Chem. Lett. 2006, 16, 2528-2531.

16. Montagner, C.; de Souza, S.M.; Groposoa, C.; Delle Monache, F.; Smânia, E.F.; Smânia, A., Jr. Antifungal activity of coumarins. Z. Naturforsch. 2008, 63c, 21-28.

17. Paya, M.; Goodwin, P.A.; De Las Heras, B.; Hoult, R.S. Superoxide scavenging activity in leukocytes and absence of cellular toxicity of a series of coumarins. Biochem. Pharmacol. 1994, 48, 445-451.

18. Fylaktakidou, K.C.; Hadjipavlou-Litina, D.J.; Litinas, K.E.; Nicolaides, D.N. Natural and synthetic coumarin derivatives with anti-inflammatory/antioxidant activities. Curr. Pharm. Des. 2004, 10, 3813-3833.

19. Horton, D.A.; Boume, G.T.; Smythe, M.L. The combinatorial synthesis of bicyclic privileged structures or privileged substructures. Chem. Rev. 2003, 103, 893-930.

20. Hadjeri, M.; Barbier, M.; Ronot, X.; Mariotte, A.M.; Boumendjel, A.; Boutonnat, J. Modulation of P-glycoprotein mediated multidrug resistance by flavonoid derivatives and analogues. J. Med. Chem. 2003, 46, 11, 2125-2131.

21. Ellis, G.P.; Barker, G. Chromone-2-and -3-carboxylic acids and their derivatives. Prog. Med. Chem. 1972, 9, 65-116.

22. Houghton, P.J. Chemistry and biological activity of natural and semi-synthetic chromone alkaloids. Stud. Nat. Prod. Chem. 2000, 21, 123-155.

23. Mallick, S.; Dutta, A.; Ghosh, J.; Maiti, S.; Mandal, A.K.; Banerjee, R.; Bandyopadhyay, C.; Pal, C. Protective therapy with novel chromone derivative against Leishmania donovani infection induces Th1 response in vivo. Chemotherapy 2011, 57, 388-393.

24. Baloch, N.; Alkahraman, Y.; Zaidi, M.; Madkour, H. Evaluation of 6, 8-Dichloro-2-methyl-4Hchromen-4-one derivatives as antileishmanial agents. Glob. J. Sci. Front. Res. Chem. 2012, 12, $26-32$.

25. Napolitano, H.B.; Silva, M.; Ellena, J.; Rodrigues, B.D.; Almeida, A.L.; Vieira, P.C.; Oliva, G.; Thiemann, O.H. Aurapten, a coumarin with growth inhibition against Leishmania major promastigotes. Braz. J. Med. Biol. Res. 2004, 37, 1847-1852.

26. Arango, V.; Robledo, S.; Séon-Méniel, B.; Figadère, B.; Cardona, W.; Saez, J.; Otalvaro, F. Coumarins from Galipea panamensis and their activity against Leishmania panamensis. J. Nat. Prod. 2010, 73, 1012-1014.

27. Pierson, J.T.; Dumètre, A.; Hutter, S.; Delmas, F.; Laget, M.; Finet, J.P.; Azas, N.; Combes, S. Synthesis and antiprotozoal activity of 4-arylcoumarins. Eur. J. Med. Chem. 2010, 45, 864-869.

28. Keith, C.T.; Borisy, A.A; Stockwell, B.R. Multicomponent therapeutics for networked systems. Nat. Rev. Drug Discov. 2005, 4, 71-78.

29. Roth, B.L.; Sheffler, D.J.; Kroeze, W.K. Magic shotguns versus magic bullets: Selectively non-selective drugs for mood disorders and schizophrenia. Nat. Rev. Drug Discov. 2004, 3, 353-359.

30. Musonda, C.C.; Whitlock, G.A.; Witty, M.J.; Brun, R.; Kaiser, M. Chloroquine-astemizole hybrids with potent in vitro and in vivo antiplasmodial activity. Bioorg. Med. Chem. Lett. 2009, 19, 481-484.

31. Meunier, B. Hybrid molecules with a dual mode of action: Dream or reality? Acc. Chem. Res. 2008, 41, 69-77.

32. Bollini, M.; Casal, J.J.; Bruno, A.M. Design, synthesis, and antitumor activity of new bis-aminomethylnaphthalenes. Bioorg. Med. Chem. 2008, 16, 8003-8010. 
33. Opsenica, I.; Opsenica, D.; Lanteri, C.A.; Anova, L.; Milhous, W.K.; Smith, K.S.; Solaja, B.A. New chimeric antimalarials with 4-aminoquinoline moiety linked to a tetraoxane skeleton. J. Med. Chem. 2008, 51, 6216-6219.

34. Walsh, J.J.; Coughlan, D.; Heneghan, N.; Gaynor, C.; Bell, A. A novel artemisinin-quinine hybrid with potent antimalarial activity. Bioorg. Med. Chem. Lett. 2007, 17, 3599-3602.

35. Peng, Y.; Song, G. Combined microwave and ultrasound assisted Williamson ether synthesis in the absence of phase-transfer catalysts. Green Chem. 2002, 4, 349-351.

36. Peyman, S.; Minoo, D.; Mohammad, A.Z.; Mohammad, A.B. Silica sulfuric acid as an efficient and reusable reagent for crossed-aldol condensation of ketones with aromatic aldehydes under solvent-free conditions. J. Braz. Chem. Soc. 2004, 15, 773-776.

37. Manhas, M.S.; Ganguly, S.N.; Mukherjee, S.; Jain, A.K.; Bose, A.K. Microwave initiated reactions: Pechmann coumarin synthesis, Biginelli reaction, and acylation. Tetrahedron Lett. 2006, 47, 2423-2425.

38. Li, S.Y.; Wang, X.B.; Xie, S.S.; Jian, N.; Wang, K.D.; Yao, H.Q.; Sun, H.B.; Kong, L.Y. Multifunctional tacrine-flavonoid hybrids with cholinergic, $\beta$-amyloid-reducing, and metal chelating properties for the treatment of Alzheimer's disease. Eur. J. Med. Chem. 2013, 69, 632-646.

39. Xie, S.S.; Wang, X.B.; Li, J.Y.; Yang, L.; Kong, L.Y. Design, synthesis and evaluation of novel tacrine-coumarin hybrids as multifunctional cholinesterase inhibitors against Alzheimer's disease. Eur. J. Med. Chem. 2013, 64, 540-553.

40. Taylor, V.M.; Cedeño, D.L.; Muñoz, D.L.; Jones, M.A.; Lash, T.D.; Young, A.M.; Constantino, M.H.; Esposito, N.; Velez, I.D.; Robledo, S.M. In vitro and in vivo studies of the utility of dimethyl and diethyl carbaporphyrin ketals in treatment of cutaneous leishmaniasis. Antimicrob. Agents Chemother. 2011, 55, 4755-4764.

41. Pulido, S.A.; Muñoz, D.L.; Restrepo, A.M.; Mesa, C.V.; Alzate, J.F.; Vélez, I.D.; Robledo, S.M. Improvement of the green fluorescent protein reporter system in Leishmania spp. for the in vitro and in vivo screening of antileishmanial drugs. Acta Trop. 2012, 122, 36-45.

42. Cardona, G.W.; Sáez, V.J. Antiprotozoal activity of $\alpha, \beta$-unsaturated d-lactones: Promising compounds for the development of new therapeutic alternatives. Trop. J. Pharm. Res. 2011, 10, 671-680.

43. Cardona, W.; Guerra, D.; Restrepo, A. Reactivity of $\delta$-substituted $\alpha, \beta$-unsaturated cyclic lactones with antileishmanial activity. Mol. Simul. 2014, 40, 477-484.

44. Otero, E.; Robledo, S.M.; Díaz, S.; Carda, M.; Muñoz, D.; Paños, J.; Vélez, I.D.; Cardona, W. Synthesis and leishmanicidal activity of cinnamic acid esters: Structure-activity relationship. Med. Chem. Res. 2014, 23, 1378-1386.

45. Finney, J.D. Probit Analysis: Statistical Treatment of the Sigmoid Response Curve, 3rd ed.; Cambridge University Press: Cambridge, UK, 1978; p. 550.

Sample Availability: Samples of the compounds are available from the authors.

(C) 2014 by the authors; licensee MDPI, Basel, Switzerland. This article is an open access article distributed under the terms and conditions of the Creative Commons Attribution license (http://creativecommons.org/licenses/by/3.0/). 